\title{
Contextual reduction of word-final /l/ in Spanish: An EPG study
}

\author{
Michael Ramsammy \\ University of Edinburgh \\ M.Ramsammy@ed.ac.uk
}

\begin{abstract}
This article presents data on the contextual reduction of /1/ in Spanish. Electropalatography (EPG) was used to examine realisations of word-final $/ 1 /$ in prevocalic and preconsonantal environments in order to determine to what extent articulatory reduction of the $/ 1 /$ is attributable to coarticulation with following segments. Previous studies using static palatography (Josselyn 1907) describe continuous RELAXATION of the articulatory stricture associated with $/ 1 /$ in different phonological environments. These descriptions, in turn, have informed standard reference works on Spanish phonetics (e.g. Navarro Tomás 1957, Gili Gaya 1966). Additionally, theoretical work on other languages has argued in favour of syllable-based accounts of /1/-allophony and reduction patterns (e.g. English /1/-darkening and vocalisation), whereas instrumental studies have revealed complexities to these patterns that challenge syllable-based analyses. The findings of the EPG study reported on here confirm that /1/-reduction in Spanish is a gradient phenomenon that arises due to antagonistic coarticulatory forces. Thus, the reduction patterns that emerge in the data cannot be predicted on the basis of syllabification algorithms alone.
\end{abstract}

\section{Introduction}

\subsection{Previous studies on /1/ in Spanish and other languages}

This study has two goals. Firstly, it aims to describe patterns of reduction affecting wordfinal $/ 1 /$ in Spanish in a range of phonetic environments on the basis of electropalatographic (EPG) data. Secondly, it relates the experimental findings to phonological questions of syllabification and to phonetic effects of coarticulation.

The articulatory variability of $/ 1 /$ in Spanish has been the subject of phonetic investigation for over a century. Based on tongue imprints collected from Peninsular Spanish speakers using static palatography, Josselyn (1907: 121ff.) reports that /1/ displays wide articulatory variability. Josselyn shows that this variability is attributable both to phonotactic contextual factors as well as idiosyncratic speech habits of subjects. For example, palatographic imprints from what Josselyn terms 'strong articulations' reveal that $/ 1$ / is sometimes articulated with full midsagittal contact across the alveolar region of the palate. Other realisations show that $/ 1 /$ may have a 'relaxed' articulation, particularly in word-final contexts. ${ }^{1}$

Josselyn's findings have informed other descriptive phonetic studies on the Spanish Language. Navarro Tomás (1957: §111) notes that relaxed articulations of /1/ - in which the tongue gently brushes against the alveolar ridge without making complete contact - occur

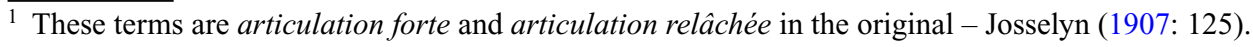


in colloquial or familiar speech (see also Navarro Tomás 1917). Likewise, Gili Gaya (1966: 147) reports that syllable-initial / $1 /$ is usually articulated with full alveolar contact, at least in careful speech. However, in syllable-final or word-final positions, relaxed /1/-articulations often occur in more casual speech styles.

Cross-dialectally, various patterns of assimilation and reduction have also been documented. Hualde (2014: 189) mentions Andalusian speech, in which certain varieties display neutralisation of $/ 1 /$ and $/ \mathrm{r} /$ in preconsonantal position and deletion of $/ 1 /$ in word-final prepausal environments: e.g. alto [arto] 'high', hospital [ohpita] 'hospital'. Neutralisation of $/ 1 /$ and $/ \mathrm{r} /$ is also noted to have a range of dialect-specific outcomes in other Spanish varieties. Guitart (1976: 23-24), for example, reports that syllable-final /1/ undergoes categorical assimilation to following sounds in the educated speech of Havana: e.g. el golpe [eg:obpe] 'the blow', el jamón [ex:amon] 'the ham' and el medio [em:eðio] 'the middle'. The same effects are observed for coda $/ \mathrm{f} /$ in this variety, both word-medially and across word boundaries: e.g. orquídea [ogkidja] 'orchid', ser padre [seb.paðre] 'to be a father', ser mejor [sem:exor] 'to be better'.2

Alba (1979) discusses the vocalisation of /1/ (i.e. desconsonantización) in syllable-final environments in the Cibaeño dialect of Dominican Spanish. In this variety, /1/ occurs as a high vocoid in examples like golpe [goi pe] 'blow', baúl lleno [bauijeno] 'full chest' and papel [papei] 'paper' (i.e. preconsonantal and prepausal environments). In intervocalic contexts, however, $/ 1 /$ is realised as a lateral consonant (e.g. dólar [dola] 'dollar'). The lateral also occurs where word-final /1/ resyllabifies across a word boundary: e.g. el hombre [e.lom.bre] 'the man', el agua [e.la.yua] 'the water'.

These descriptions, whilst largely impressionistic, confirm that /1/ in Spanish displays interesting patterns of variability that bear similarities to those reported for other languages on the basis of instrumental data. For example, Hardcastle \& Barry (1989) studied the reduction of coda /1/ in English in different preconsonantal contexts using EPG. Traditional phonological analyses of English (e.g. Chomsky \& Halle 1968) describe an allophonic pattern which causes /1/ to have a 'light' realisation in onset positions (i.e. [1]) and a 'dark' realisation (i.e. [1]) in coda positions. Further to this, a number of dialects exhibit coda /1/vocalisation (Tollfree 1999, Johnson \& Britain 2007). Hardcastle \& Barry's results reveal that the degree to which /1/ undergoes reduction or vocalisation depends both on subject-specific speech habits and phonotactic factors. With regard to the phonotactic factors, the place of articulation of the consonant in /1C/-clusters has a robust effect: /1/-vocalisation (to [ $\gamma$ ], [ö] or $[\mho]$ ) occurs most frequently before velar consonants, somewhat less frequently before palatoalveolar consonants, and least frequently before following alveolar consonants. Furthermore, the preceding vowel exerts an influence: Hardcastle \& Barry observe a tendency for $/ 1 /$ to vocalise more frequently after front vowels than after back vowels.

Additionally, a study carried out by Scobbie \& Pouplier (2010) provides further insights on patterns of reduction and vocalisation in English word-final /1/. Comparison of EPG data from speakers of Scottish English and Southern British English shows that Scottish speakers vocalise word-final /1/ more frequently than the English speakers, both preconsonantally (before $/ \mathrm{b} /$ and $/ \mathrm{h} /$ ) and prevocalically. The five English participants in the study generally displayed more conservative patterns: two speakers consistently vocalised before $/ \mathrm{b} /$, but not before $/ \mathrm{h} /$; two other speakers vocalised only sporadically; and for the other English participant, word-final /1/ always had a consonantal realisation. Prevocalically, none of the English participants exhibited vocalisation, whereas evidence of vocalisation in this environment was observed in almost all tokens produced by two of the Scottish speakers. Two other Scottish speakers vocalised $/ 1 /$ in approximately $40-50 \%$ of prevocalic tokens. These results therefore echo Hardcastle \& Barry's finding that articulatory reduction and vocalisation of /1/ in English displays clear idiolectal trends of variation, as well as interdialectal variation.

\footnotetext{
${ }^{2}$ Regarding clusters such as [gk] and [bp], Guitart notes that coda $/ 1 /$ and $/ \mathrm{f} /$ assimilate in place and manner to following obstruents, but not in voicing.
} 
In addition, since distinct rates of vocalisation are observed word-finally before different word-initial consonants and before following vowels, these data raise important challenges for analyses of $/ 1 /$-vocalisation which attempt to predict the articulatory behaviour of $/ 1 /$ on the basis of syllabification.

Gibbon, Hardcastle \& Nicolaidis (1993) examined the spacio-temporal properties of $/ \mathrm{kl} /$ sequences in six European languages. As well as interesting asymmetries in degree of overlap for $/ \mathrm{k} /$ and $/ \mathrm{l} /$ that depend upon surrounding vowels, some evidence for language-specific patterns of articulatory reduction and overlap was also found. For example, Catalan speakers in this study tended to overlap $/ \mathrm{k} /$ and $/ 1 /$-gestures most extremely, whereas Swedish speakers showed no overlap tendency. The authors note that this result emerges because the articulation of Catalan dark $/ 1 /$ is more gesturally compatible with the dorsal gesture for $/ \mathrm{k} /$, and this therefore results in a strong tendency for coarticulation in $/ \mathrm{kl} /$-clusters. In Swedish, not only is the language-specific light /1/ less compatible with /k/ - in other words, /k/ and light /1/ display ARTICULATORY ANTAGONISM (Recasens, Pallarès \& Fontdevila 1998, Recasens \& Pallarès 2001 ) - but $/ \mathrm{kl} /$-clusters are typically heteromorphemic in Swedish, and stress placement may also play a role (Gibbon et al. 1993: 174). Strong speaker-specific trends were also observed for the other languages studied, namely English, French, German, and Italian (see Hardcastle 1985 for further data on English and Bombien et al. (2010) on /kl/-sequences in German).

Further phonetic work on Catalan provides useful contextualisation for studying lateral articulations in Spanish. For example, Recasens (2004) discusses dialect-specific variation in the articulation of /1/. EPG data collected from speakers of Mallorcan Catalan, Eastern Catalan and Valencian Catalan provides evidence for different degrees of darkening in intervocalic /1/-realisations. Speakers of the Mallorquí variety show the darkest realisations: palatograms from these speakers confirm that intervocalic /1/ is produced with a lowered and retracted tongue-dorsum and relatively reduced linguo-alveolar contact. At the other end of the scale, speakers of Valencià display characteristically light /1/-realisations. Palatograms extracted from intervocalic /1/ tokens produced by these speakers show full contact in the anterior region of the palate, and also high levels of activation of the peripheral electrodes along both sides of the palate in anterior and posterior contact regions. The Eastern Catalan speakers produce /1/-realisations that fall between these extremes. The darkness of intervocalic /1/ in Eastern Catalan is less extreme than in the Mallorquí dialect, but the anterior/peripheral contact that characterises /1/-lightness is also less robust than in tokens produced by the Valencià speakers (see also Recasens \& Espinosa 2007 for articulatory comparisons of rhotic consonants in Valencià and Eastern Catalan, and Simonet 2010b for acoustic comparisons of /1/-realisations in Catalan-Spanish bilingual speech).

Regarding coarticulation, Calatan /1/ shows behaviour that distinguishes it from other sonorants. For example, Recasens (1996) notes that both Catalan dark /1/ and German light $/ 1 /$ resist coarticulation with flanking vowels to a greater extent than $/ \mathrm{n} /$ or $/ \mathrm{r} /$. Conversely, dorsum retraction in Catalan dark /1/ significantly affects the quality of preceding vowels (Recasens, Pallarès \& Fontdevila 1997). This is to say that whilst Catalan /1/ itself is the source of strong C-to-V coarticulatory effects, it is less robustly affected by V-to-C coarticulation than other sonorants. For Spanish, however, Martínez Celdrán \& Fernández Planas (2007: §3) observe on the basis of EPG data that $/ 1 /$ and $/ \mathrm{n} /$ are similarly affected by vocalic context, at least in the dorsal region. Both /ana/ and /ala/-realisations display less dorsal contact than /ini/-/ili/ and /unu/-/ulu/, respectively. Furthermore, tongue-tip contact for /1/ tends to be more advanced in front-vowel contexts (i.e. /ili/) than in central and back contexts, i.e. /ala/ and /ulu/ (Martínez Celdrán \& Fernández Planas 2007: 138). Nevertheless, comparisons of /1/-realisations produced by 4 Spanish speakers in Fernández Planas (2000: 167-169) shows that this pattern is not consistent across speakers, and there is also intraspeaker variation. ${ }^{3}$ Fernández Planas (2000: 240) also argues that Spanish /1/ is somewhat

\footnotetext{
${ }^{3}$ Fernández Planas (2000: 237-240) also notes that these Spanish speakers, all of whom were resident in Catalonia at the time of recording, produce partially velarised /1/-realisations. This is attributed to influence from Catalan.
} 
less sensitive to vocalic coarticulatory effects than $/ \mathrm{n} /$ (i.e. on a scale of decreasing sensitivity to coarticulatory effects, $[\mathrm{r}>\mathrm{n}>1>\mathrm{s}>\mathrm{r}]$ ).

With respect to C-to-C coarticulation, instrumental work has tended to focus on the behaviour of nasals in Spanish. As is the case with English, these studies have unearthed complexities that are not necessarily predicted by phonological descriptions of the language. Harris (1984) claims that the place of articulation of syllable-final nasals is dependent upon following consonants: i.e. that feature-spread operations produce patterns of categorical assimilation in NC-sequences, e.g. [kam.po] 'field', [man.ko] 'one-handed' and [pam.bune.no] 'good bread', [pay.ka.ro] 'expensive bread'. However, Ramsammy (2012) argues on the basis of acoustic and EPG data that assimilation in NC and N\#C-clusters in Peninsular Spanish is characterised by gradience and speaker-specific articulation strategies. More specifically, the outcome of assimilation depends on an interaction of factors, including the phonetic properties of the post-nasal sound, the type of boundary (prosodic or morphosyntactic) that intervenes between the nasal and the following consonant, and the dialect-specific realisation of word-final nasals in non-assimilation environments (i.e. as alveolar [n] or velar [y]). Further EPG work carried out by Kochetov \& Colantoni (2011b) shows that assimilation in NC-clusters can be categorical in Argentinian and Cuban varieties, typically where $\mathrm{C}$ is a stop. In other contexts, for example in nasal-fricative sequences, assimilation is more gradient and dependent on dialectal factors and speaker-specific coarticulation strategies. The results of this study therefore resemble the findings of Honorof (1999), where EMA data from Peninsular Spanish speakers indicate that syllable-final nasals have similar stricture targets to following obstruents. More generally, these studies confirm that coarticulation in NC-clusters in Spanish is complex, and the articulatory patterns of syllable-final nasals are not entirely predictable on the basis of the phonological properties of following consonants. Similar results also emerge from EPG studies on other languages: e.g. Italian (Farnetani \& Busà 1994, Celata et al. 2013), English (Ellis \& Hardcastle 2002) and French (Steele, Colantoni \& Kochetov 2019).

The findings of existing research therefore leave outstanding questions concerning the articulatory behaviour of /1/ in Spanish. Evidence for /1/-reduction was reported as far back as in Josselyn's (1907) study; however, there is a lack of research on these patterns using modern articulatory imaging techniques. In addition - and unlike what has been described for nasals phonological descriptions of Spanish have not identified processes of feature sharing between laterals and surrounding sounds. However, the phonological distribution of laterals in the language is almost identical to that of nasals, which suggests that laterals should be sensitive to some of the same structural constraints. As already noted for Cibaeño (Alba 1979), /1/ may display different phonetic properties depending on its phonological patterning in coda vs onset positions (and, potentially, also in derived-onset contexts). Thus, an outstanding issue is to what extent $/ 1 /$-reduction patterns can or cannot be predicted by syllabification generalisations.

\subsection{Syllabification and resyllabification in Spanish}

There is general agreement in phonological descriptions of Spanish as to how syllables are structured in the language. The maximal syllable shape is CCVCC (e.g. [trans.pa.ren.te] 'transparent'), and onsetless syllables are tolerated word-initially (e.g. uva [u.ßa] 'grape'). Word-medially, a range of consonants occur in coda position, with liquids, nasals and the fricatives /s/ and / $\theta$ / being particularly common (Hualde 2014: 62). Furthermore, /n 1 r s $\theta$ d/ are the only sounds that regularly occur word-finally in the language. ${ }^{4}$

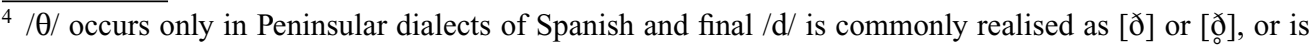
otherwise deleted. Other word-final consonants do occur in the language, but these are much rarer: e.g. / $\mathrm{x} /$ in reloj 'clock' and others (including certain consonant clusters) in loan vocabulary (such as /klip/ 'paperclip', /tfef/ 'chef', /roßots/ 'robots', etc.).
} 
Regarding VCV sequences, the consensus is that intervocalic consonants exceptionlessly syllabify with following vowels. Of particular relevance to the current study is the claim that this process applies both word-medially and across word boundaries. Theoretical and descriptive work on Spanish consistently highlights the operation of categorical resyllabification in /-VC\#V-/ sequences, e.g. [klúß.la.tí.no] 'Latin American club' vs [klú.ßes.pa.nól] 'Spanish club’ (Hualde 2014: 74-76, ${ }^{5}$ see also Macpherson 1975: §5.13, p. 36; Hualde 1991a; Colina 1997, 2006, 2009: 45-51). Navarro Tomás (1957: §154) also provides various examples of this type of resyllabification (e.g. el oro [e.lo.ro] 'the gold'), commenting that 'the final consonant of a word, when in contact with the initial vowel of a following word, is treated as intervocalic in rapid speech, and groups syllabically with said initial vowel' ${ }^{6}$ Lipski (1989: 53) adds that resyllabification is 'nearly exceptionless' in rapid speech, whereas it may be blocked in slower, more formal speaking styles. Colina (1995: 26) further highlights that resyllabification affects single intervocalic consonants (in Catalan and Galician, as well as in Spanish), such that '[a]1l three languages resyllabify C.V across words, but not C.CV, even if the resulting cluster would be permissible'; hence, * [klú.ßla.tí.no].

This situation contrasts with phonological studies on English in which there is less general agreement about resyllabification across word boundaries. As mentioned, an oftenencountered statement is that $/ 1 /$ is light in the onset and dark in the coda. However, various experimental studies have shown this assumption to be problematic. For example, Turton (2014, 2017) shows that English /1/-darkening varies across dialects, and that some patterns display sensitivity to morphosyntactic boundaries. Ultrasound data reveal that speakers of $\mathrm{RP}$ and London English use a darker variant of /1/ with more extensive tongue-dorsum raising and retraction in canonical coda positions (i.e. utterance-finally and preconsonantally), whereas prevocalic /1/-realisations are much lighter, involving a dominant tongue-tip gesture. This finding, on the one hand, might be interpreted as providing evidence that word-final /1/ resyllabifies into onset position in English in prevocalic contexts, thereby escaping the phonological environment in which allophonic darkening in triggered. However, in other dialects (e.g. Essex English, General American English), the patterns are more complex, suggesting more fine-grained distinctions that evade a straightforward syllable-based analysis (recall Scobbie \& Pouplier's 2010 EPG study discussed above; Sproat \& Fujimura 1993, Lee-Kim, Davidson \& Hwang 2013).

For Spanish, various pieces of evidence have been presented to illustrate the application of categorical resyllabification across word boundaries. A frequently mentioned example is emphatic trilling of $/ \mathrm{f} /$. Word-final coda $/ \mathrm{f} /$ in Spanish can optionally be realised either as a tap or a trill (with the trill being characteristic of emphatic speech): e.g. [mar] or [mar] 'sea' (Harris 1983: 70-71). However, emphatic trilling is blocked in word-final prevocalic environments: thus, only a tap can occur in examples like mar azul 'blue sea'. Since emphatic trilling is restricted to coda position, the fact that word-final $/ \mathrm{r} /$ never undergoes trilling in prevocalic environments is argued to be evidence for the operation of a resyllabification process that converts /mar\#aOul/ into [ma.ra.Өul] (*[ma.ra.Oul], even under emphasis; see also Lipski 1990: 155-156; Bermúdez-Otero 2011). Similarly, numerous dialects of Spanish display aspiration of coda /s/ in word-final environments: e.g. [mareh] 'seas'. However, in certain dialects, aspiration fails to occur prevocalically in examples like mares azules 'blue seas' (see Kaisse 1999 on Argentinian Spanish; and relatedly, see Hualde 1991b on the non-aspiration of /ð/ in word-final prevocalic contexts in the Chinato dialect). ${ }^{7}$ Just like word-final prevocalic $/ \mathrm{f} /$, the

\footnotetext{
5 This publication follows the convention of using acute accents to indicate word stress.

${ }^{6}$ Author's translation of 'la consonante final de una palabra, en contacto con la vocal inicial de una palabra siguiente, se trata también como intervocálica en la pronunciación rápida, agrupándola silábicamente con dicha vocal inicial'.

7 The Chinato word-final /ð/ in question corresponds to word-final /s/ in standard dialects of Spanish; see Hualde (1991b: 57-62) for details.
} 
failure of final /s/ (and Chinato final / $/$ /) to aspirate before vowel-initial words has been interpreted as further evidence for resyllabification of word-final consonants into onset position across a word boundary: i.e. [ma.re.sa.su.leh].

Despite these facts, the phonetic consequences of resyllabification remain largely unclear. There is some evidence, for example, that word-final intervocalic $/ \mathrm{s} /$ is treated in the same way as word-medial intervocalic /s/ as being a target for gradient voicing in Quito Spanish (Strycharczuk et al. 2014). Yet with regard to /1/-reduction, it remains to be seen to what extent the articulatory profile of putative derived-onset /1/ in VC\#V sequences may or may not differ from that of $/ 1 /$ in canonical coda positions.

\subsection{The present study}

Given that the earliest descriptions of /1/-reduction in Spanish rely on static palatographic images, the first goal of this study is to provide a more accurate, quantifiable description of this phenomenon using electropalatography. The second goal is to assess to what extent articulatory reduction of /1/ is dependent on coarticulation with surrounding segments, and whether the reduction patterns can be predicted on the basis of syllabification or not. Analysis of EPG data ultimately shows that assumptions about the syllabic affiliation of word-final /1/ do not make strong predictions about articulatory reduction. On the contrary, /1/-reduction is best explained as the outcome of competing coarticulatory forces that operate independently of syllabification.

The paper is organised as follows. Section 2 presents an overview of the experiment design and methodology. The results are presented in Section 3. Section 4 discusses how the experimental findings bear upon (i) resyllabification of final consonants across word boundaries, and (ii) the role of coarticulation in the articulatory relaxation of /1/ in Spanish. Section 5 concludes the paper.

\section{Methods}

\subsection{Data collection}

Electropalatography was used to examine the realisation of word-final $/ 1 /$ in a range of environments. These included (i) word-final prepausal position, (ii) word-final prevocalic position, and (iii) word-final preconsonantal position before obstruents contrasting both in place-of-articulation features (i.e. labial vs dorsal) and manner-of-articulation (i.e. stops vs fricatives). Participants were custom-fitted for Articulate-style electropalates (Articulate Instruments Ltd.) which contain 62 electrodes arranged in eight rows. Recordings were carried out in a sound-attenuated studio. Simultaneous acoustic and EPG data were recorded using the WinEPG system equipped with the Articulate Assistant Advanced software package (Wrench 2003-2019). Audio data were sampled at $44.1 \mathrm{kHz}$ and EPG data were sampled at 200 frames per second.

\subsubsection{Participants}

Four participants were recruited for the experiment: all were naive as to the purpose of the study and none reported any speech or hearing pathologies. Speaker S1 is male and originally from Galicia. Speaker S2 is a female from Ciudad Real. Speakers S3 and S4 are both female and both from Galicia. Speakers S1 and S3 are Spanish-Galician bilinguals. S4 reported some passive familiarity with Galician, but no active use of the language. These speakers represent a convenience sample for whom EPG palates were available at the time of recording. They had previously also taken part in EPG experiments designed to test the realisation 
Table 1 Test conditions used in the experiment.

\begin{tabular}{|c|c|c|}
\hline Context & Test sequence & Gloss \\
\hline a. /-1\#\#/ & $\|$ & \\
\hline b. /-1\#V-/ & _ azul & 'blue ___ ' \\
\hline c. /-1\#p-/ & palmero & '__ f from La Palma' \\
\hline d. /-1\#f-/ & _famoso & 'famous ___ ' \\
\hline e. $/-1 \# \mathrm{k}-/$ & catalán & 'Catalan \\
\hline f. /-1\#x-/ & jamaicano & 'Jamaican _ \\
\hline
\end{tabular}

of word-final nasals (Ramsammy 2012, 2013). ${ }^{8}$ Prior to participating in the experiment, speakers wore the pseudo-palates for an acclimatisation period of one hour (see Hardcastle et al. 1989, McAuliffe, Robb \& Murdoch 2007). All speakers had gained a minimum of five hours' previous experience of speaking whilst wearing a palate before recording data for the experiment reported on here.

\subsubsection{Stimuli}

The experimental stimuli consisted of a series of nonce words embedded in a carrier phrase (e.g. Les mandó un febel azul 'S/he sent them a blue febel'). Nonce items all had the form $/ \mathrm{CVCel} /$. Contextual realisations of /1/ were tested by systematically varying the word that occurred immediately after the nonce-item on a sentence-by-sentence basis. This meant that /1/ is always preceded by a stressed vowel and followed by a voiceless consonant and an unstressed vowel. As shown in Table 1(a), prepausal /1/-realisations were tested by placing nonce-words in absolute phrase-final position. Testing the realisation of $/ 1 /$ in contexts (a)-(f) allows for a number of key questions about the contextual variability of $/ 1 /$ to be addressed. Comparison of (a) word-final prepausal /1/-realisations with (b) word-final prevocalic /1/-realisations allows for important observations about the articulatory 'relaxation' of intervocalic /1/ in Spanish to be made Josselyn 1907: 121-126; Navarro Tomás 1957: §111). Comparing the articulatory properties of word-final /1/ in contexts (c)-(d) and (e)-(f) makes it possible to assess to what extent the realisation of a following linguo-palatal articulation target (i.e. for $/ \mathrm{k} /$ or $/ \mathrm{x} /$ ) may have a greater or lesser reductive effect on the articulatory magnitude of the preceding $/ \mathrm{l} /$ than a following labial articulation (i.e. $/ \mathrm{p} /$ or $/ \mathrm{f} /$ ). Testing the articulation of $/ 1 /$ before following stops and following fricatives also permits examination of the relative contribution that consonants differing in stricture properties make to the reduction of coda $/ 1 /$.

The use of nonce words rather than lexical words has certain advantages for investigating the articulatory properties of $/ 1 /$ in different phonotactic contexts. Firstly, this method allows for $/ 1 /$ and $/ \mathrm{lC} /$-realisations to be tested in a single vocalic context: observe that in each of the phrase-medial test conditions listed in Table 1 (i.e. contexts (b)-(f)), the target $/ 1 /$ was preceded by a stressed /e/ and followed consistently by an unstressed /(C)a/-sequence. Secondly, given that more frequent lexical words may display a greater tendency for phonetic reduction

\footnotetext{
${ }^{8}$ Speakers from Galicia were recruited for this work due to the occurrence of word-final [ $\left.\mathrm{y}\right]$ in Galician and Galician Spanish varieties. Relatedly, an anonymous reviewer queries whether /1/ in Galician is clear or dark. Regueira (1996) notes that Galician has a clear lateral phoneme, /1/, which contrasts with $/ K /$ for some speakers (see also Freixeiro Mato 1998). In coda position, /1/ shows evidence of coarticulation with following obstruents, but it is articulated as [1] elsewhere. Whilst potential influence from Galician cannot be discounted for the bilingual participants, both S1 and S3 report regularly using Spanish in their daily lives. S1 expresses a preference for using Galician with close family, whereas S3 mostly uses Spanish with her family.
} 
(A)

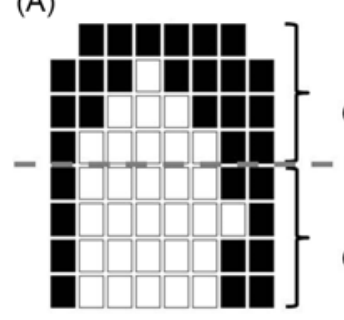

$\mathrm{APC}=0.7$

$\mathrm{PPC}=0.344$
(B)

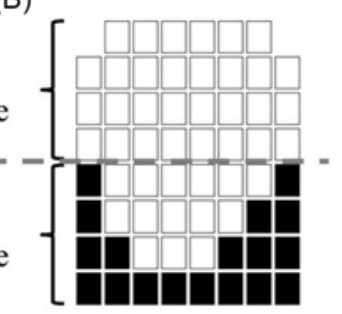

$\mathrm{APC}=0$

$\mathrm{PPC}=0.563$

Figure 1 EPG measurement zones. Palatograms used for illustration here were extracted from contact maxima in single realisations of (a) $/ \mathrm{t} /$ and (b) $/ \mathrm{k} /$ produced by speaker $S 1$.

(Bybee 2000), the use of nonce words may help to minimise potential word-frequency effects in the data. Thirdly, constructing nonce words in a controlled way may also reduce the likelihood that phonotactic frequency might exert effects on the realisation of the target sequences. For this purpose, the extra phonological material all nonce-items - i.e. the initial /CVC/ that did not form part of the /-el\#(C)a-/ target sequence - was supplied by a random combination of any of the labial and coronal obstruents of Spanish (i.e. /p b f t d $\theta \mathrm{s} /$ ) and a randomly selected vowel $(/ \mathrm{i} /$, , e/, or $/ \mathrm{a} /)$. The back rounded vowels $(/ \mathrm{u} /$ and $/ \mathrm{o} /)$ and dorsal consonants were not used for the construction of nonce words because of the possibility that these sounds may induce greater coarticulatory effects upon flanking segments (see Recasens \& Pallarès 2001 for evidence from Catalan).

In addition to varying the segmental content of the nonce-words, the carrier phrase was exploited in an attempt to divert speakers' attention away from the target sequences, and to counteract list-reading effects. Rather than using a uniform formulation, the test sequences listed in Table 1 were instead randomly embedded in one of 10 different carrier phrases (see Scobbie \& Pouplier 2010: 244 on the use of variable carrier sentences). A complete list of carrier phrases used for this experiment is given in Appendix A.

Fifteen repeats of each test sequence were recorded per speaker. Of these, data from two repetitions were discarded: ${ }^{9}$ thus, data from 13 repeats of each test sequence were subjected to statistical analysis for each speaker. Test sentences were presented to speakers in a fully randomised order. Other randomly ordered test sentences designed for different experimental purposes (not discussed here) were also recorded. The number of additional sentences exceeds the number of target sentences on which the analysis presented in Section 3 below is based. These additional phrases served as distracters for testing word-final /1/-realisations in the contexts listed in Table 1.

\subsection{Data reduction}

\subsubsection{EPG analysis variables}

Tongue-palate contact was measured using two EPG analysis variables: (i) ANTERIOR PAlatal CONTACT (APC), and (ii) POSTERIOR PAlatal CONTACT (PPC). These variables quantify the degree of contact in the anterior and posterior sections of the palate, respectively. The formulae used for the calculation of these analysis variables are given in Appendix B. As shown in Figure 1, high levels of contact yield high values for these variables, whereas

\footnotetext{
9 The first repetition was excluded as this was used to familiarise the participants with the stimuli and check equipment functionality. A further set was excluded due to experimenter error.
} 


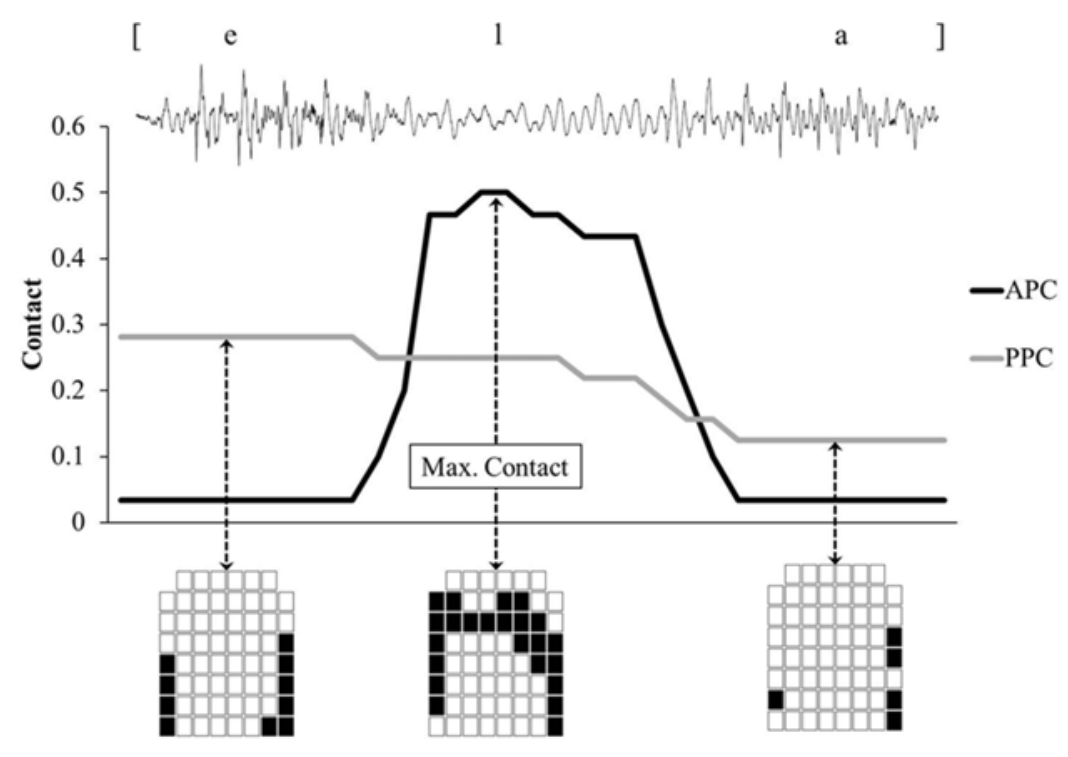

Figure 2 The point of maximal linguo-palatal contact.

low-magnitude contact yields low values (see Recasens \& Pallarès 2001: 283 and Kochetov $\&$ Colantoni 2011a: 320 on the use of similar measurements based on contact in anterior and posterior zones).

EPG contact measurements for all /1/-realisations were extracted at the point of maximal contact in the APC zone. As illustrated in Figure 2, the point of maximal contact was defined as the EPG frame coinciding with a peak in the APC contour.

\subsubsection{Durational measurements}

In addition to the EPG contact measurements, two durational measurements were calculated (see Figure 3). Firstly, TONGUE TIP CONTACT DURATION (henceforth, TTC-Dur) is a measurement of the period over which contacts in the Anterior Zone are activated in /1/-realisations. ${ }^{10}$ Secondly, /L\#C/-DURATION (/l\#C/-Dur) quantifies the duration of /1\#C/clusters that were tested in the experiment. In clusters containing a word-initial stop, $/ \mathrm{A} \mathrm{C} /$-Dur quantifies the lag between the first EPG frame displaying contact in the anterior section of the palate and the EPG frame coinciding with the stop burst. For clusters containing a word-initial fricative, /1\#C/-Dur quantifies the lag between the first EPG frame in the /1/realisation displaying contact in the anterior zone and the offset of frication of the word-initial fricative (i.e. /f/ or / $/$ /). Combining analysis of tongue-contact measurements with durational measurements crucially permits questions about the temporal and spacial reduction of $/ 1 /$ in different segmental contexts to be addressed.

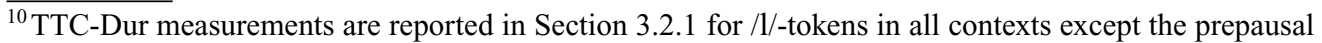
context. This is because TTC-Dur is calculated based on EPG contact data: the onset and offset of gestures as measured by EPG therefore often do not align with acoustic events that are identifiable from visual inspection of corresponding waveforms and spectrograms. In the case of prepausal /1/, speakers sometimes held the tongue in an /1/-like configuration well after the offset of periodic voicing and the disappearance of formant structure in the spectrogram. Because of this, durational measurements for prepausal /1/ cannot reliable be extracted from the EPG contact data alone. An alternative measure was therefore employed for prepausal /1/-tokens (see Appendix D for further details).
} 


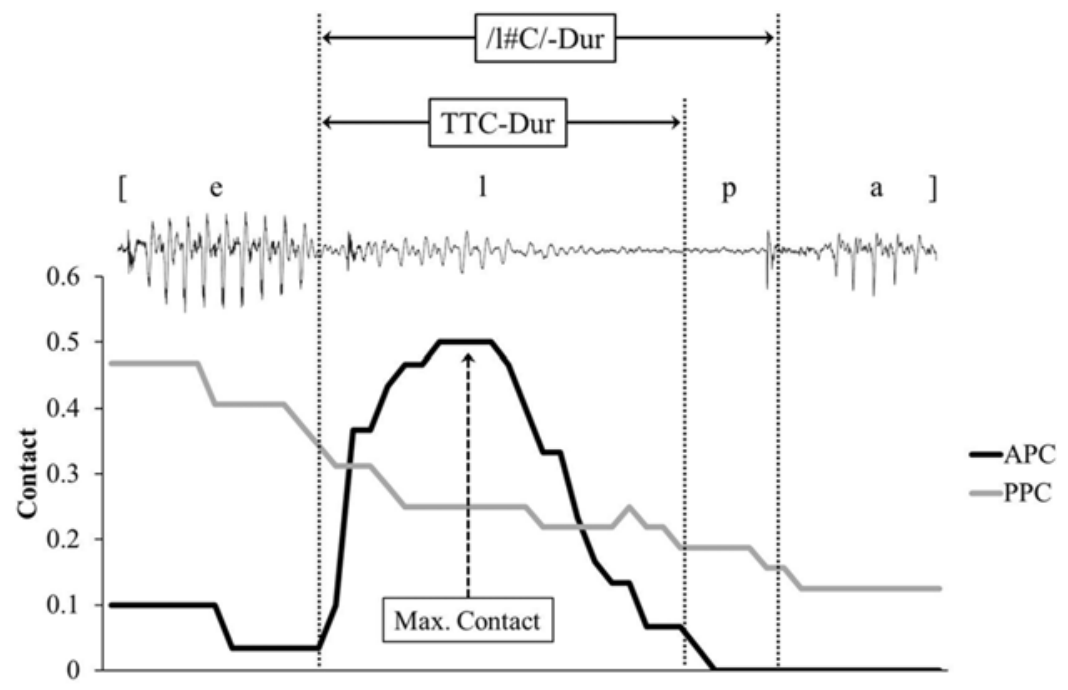

Figure 3 Durational measurements.

\subsection{Statistical analysis}

Statistical analysis using linear mixed-effects regression was performed on the EPG data using the lme 4 package (Bates et al. 2014) in $R$ (R Development Core Team 2015). $P$-values for fixed effects were estimated using the lmerTest package (Kuznetsova, Brockhoff $\&$ Christensen 2017). In the analyses reported in Section 3.2 below, the dependent variables were APC (Section 3.2.1) and PPC (Section 3.2.2). Pooled values for all tokens from all speakers are included in the datasets. In the initial models, Context was included as a fixed effect and Speaker was modelled as a random effect. These models were then compared to two alternative models which included an additional random intercept for [1]-duration (see Figure 6, Section 3.1 below). This resulted in a significant improvement in model fit for APC (as assessed by a log-likelihood test: $\chi^{2}=24.12, p<.001$ ). For PPC, inclusion of a random intercept for [1]-duration resulted only in a minor and non-significant improvement of fit $\left(\chi^{2}=2.42, p>.1\right)$. This structure was nevertheless retained to preserve symmetry between the APC and PPC models. Following calculation of these models, post-hoc testing was performed using pairwise $t$-tests with conservative Bonferroni adjustments in order to compare the relative significance of individual levels of the Context factor.

\section{Results}

\subsection{Durational measurements}

Analysis of durational measurements provides initial evidence that $/ 1 /$ is sensitive to reduction in different phonotactic contexts. Figure 4 (upper panel) shows mean values for TTC-Dur for all test conditions in which data could reliably be extracted. As noted in Section 2.2.2 above, an alternative durational measurement was used for prepausal /1/. Values for this are plotted for each of the four speakers in the lower panel of Figure 4.

A number of relevant observations can be made on the basis of these data. For example, prepausal / $1 /$ is longest for all speakers: averaging across speakers, that is around $36 \mathrm{~ms}$ longer than the longest phrase-medial /1/ realisations (i.e. /l\#p/). Comparison of TTC-Dur values in contexts (b) and (c) reveals that, on average, word-final /1/-realisations are shorter 

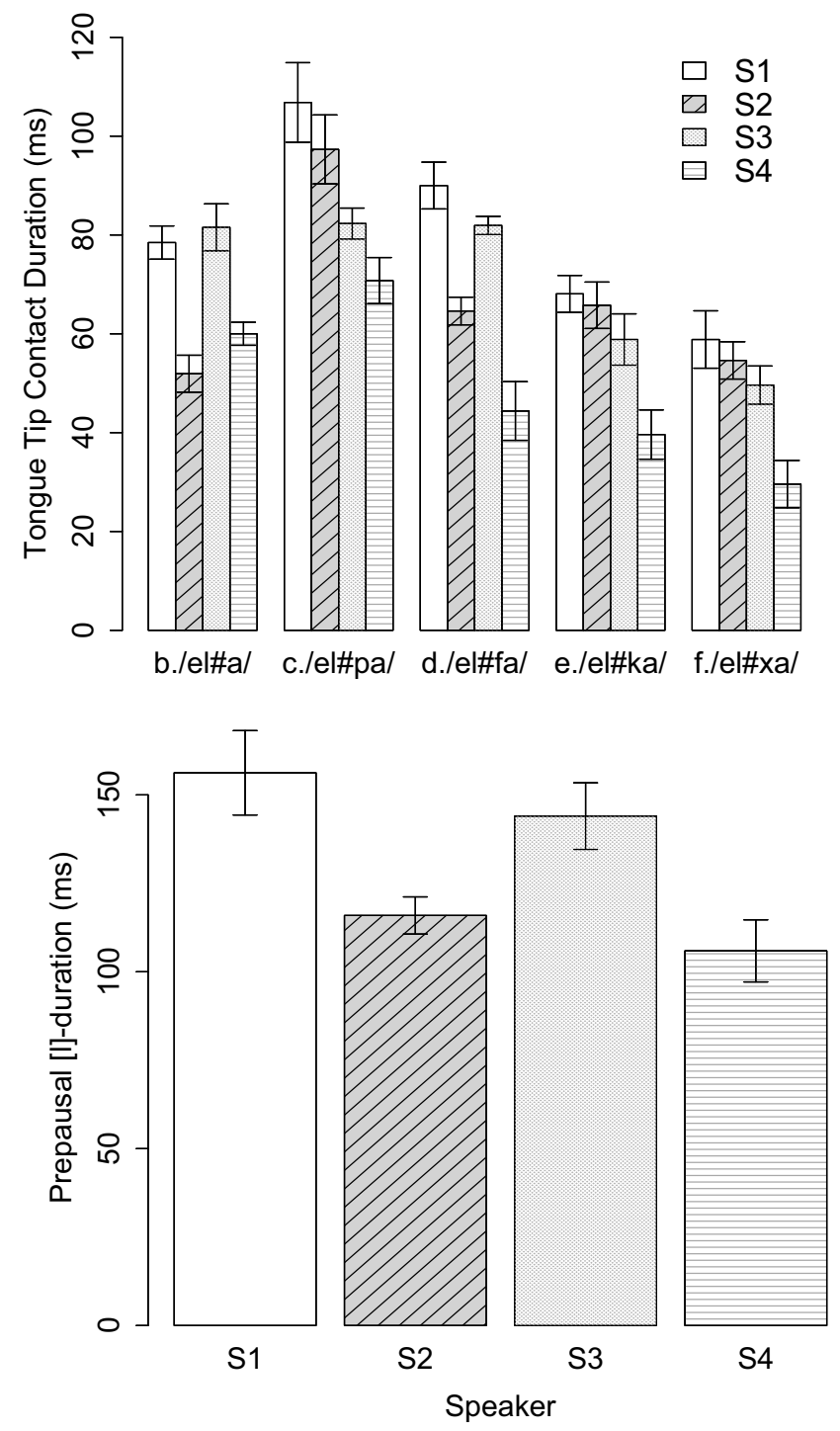

Figure 4 TTC-Duration in test contexts (b)-(f) (upper panel) and acoustic duration of prepausal [1] (lower panel). Error bars show 95\% confidence intervals.

prevocalically than in the $/ 1 \# \mathrm{p} /$ environment. Whilst this effect can be observed for all speakers, it is particularly strong for S2: the mean value for TTC-Dur in / $/ \# \mathrm{p} /$ is $97.3 \mathrm{~ms}$ for this speaker, which is almost double the mean duration of word-final prevocalic /1/ (51.9 ms see Appendix C for a full table of values). In addition, the mean TTC-Dur value in the / $\# \mathrm{f} /$ context is also observably higher than prevocalic /1/ for S1 and S2. Interestingly, S4 exhibits the opposite pattern: /1/ before /f/ is much shorter than prevocalic /1/ for this speaker. For S3, differences in TTC-Dur values between $/ 1 \mathrm{Ha} /, / 1 \mathrm{Hp} /$ and /1\#f/ are marginal. However, comparison of values in environments $(\mathrm{c}-\mathrm{f})$ does reveal a trend: there is a progressive decrease in TTC-Dur values across the preconsonantal contexts such that $/ 1 /$ is longest before $/ \mathrm{p} /$ and shortest before $/ \mathrm{x} /$. 


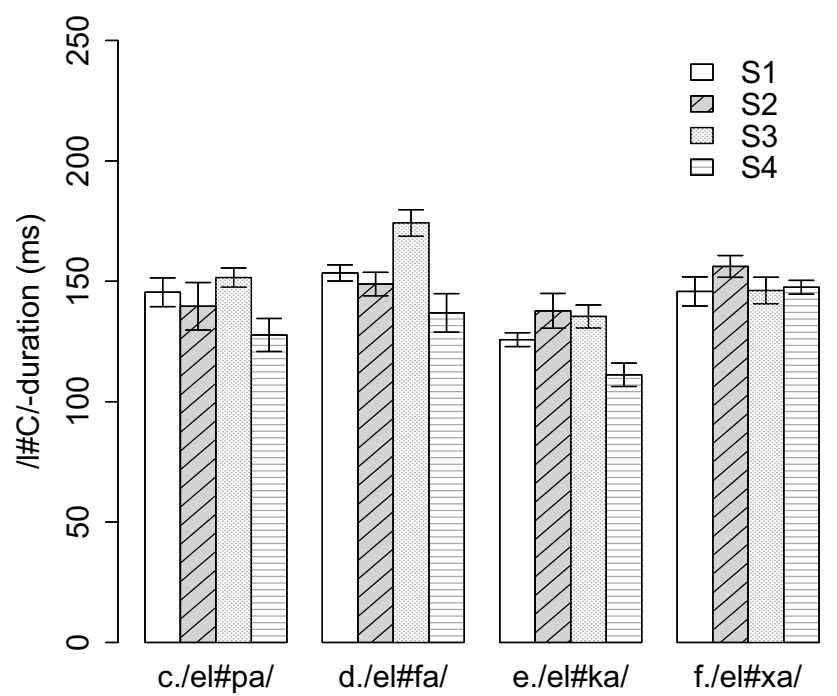

Figure 5 /1\#C/-Duration measurements. Error bars show 95\% confidence intervals.

Visual inspection of the / $1 \# \mathrm{C} /$-Dur data shown in Figure 5 below reveals that contextual differences in $/ \mathrm{A} \mathrm{AC}$-duration are less robust than TTC-duration. Observe that for all speakers, the $/ \mathrm{l} \mathrm{HC} /$ clusters in which the word-initial obstruent is a fricative are longer than when the word-initial obstruent is a stop, if only marginally so in some cases. Furthermore, for all speakers except $\mathrm{S} 2$, the duration of $/ \mathrm{l} \# \mathrm{p} /$ is longer than that of $/ 1 \mathrm{Hk} /$. Seen in the context of the fact that TTC-Dur values are also much lower in $/ 1 \# \mathrm{k} /$ than $/ 1 \# \mathrm{p} /$, this suggests that the velar stop may produce more of a reductive effect on $/ 1 /$ than a labial stop.

In the fricative contexts here, there are obvious speaker-specific differences. / $\mathrm{l} \mathrm{f} /$ appears to be substantially longer than $/ 1 \mathrm{H}$ / for speaker $\mathrm{S} 3$ (i.e. a difference of $18 \mathrm{~ms}$, on average). $\mathrm{S} 1$ exhibits the same tendency, although the difference is marginal (i.e. $7.7 \mathrm{~ms}$ on average). The opposite pattern is observed for $\mathrm{S} 2$ and $\mathrm{S} 4$, both of whom display a relatively minor difference between $/ \mathrm{l} \# \mathrm{f} /$ and $/ \mathrm{l} \# \mathrm{x} /$, with $/ \mathrm{l} \# \mathrm{C} /$-duration values in the latter context being slightly longer than in the former context (i.e. a difference of $7.4 \mathrm{~ms}$ for S2 and $10.6 \mathrm{~ms}$ for S4).

Despite these speaker-specific differences, a clearer overall picture of how the place and stricture targets of following obstruents affect the duration of the preceding / / emerges when TTC-duration values are expressed proportionally to $/ \mathrm{l} \# \mathrm{C} /$-duration values. This is shown in Figure 6 (upper panel) with values for all four speakers pooled per context. From this, it is clear, firstly, that stop consonants produce less of a reductive durational effect on preceding $/ 1 /$ than fricatives at both places of articulation tested here. Secondly, durational reduction on $/ 1 /$ is generally greater in the context of dorsal consonants than it is in the context of labial consonants.

Finally, the lower panel of Figure 6 shows normalised [1]-duration values per context. Here, pooled values from the four speakers provide a further visualisation of the more general

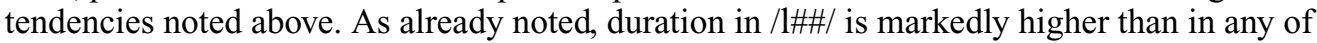
the phrase-medial test contexts. Within the phrase-medial environments, TTC-Dur is highest in $/ \mathrm{l} \# \mathrm{p} /$ and lowest in $/ \mathrm{l} \# \mathrm{x} /$. As mentioned in Section 2.3 above, the mixed-effects regression models for APC and PPC discussed in Section 3.2.1 and Section 3.2.2 below, respectively, include a random intercept for [1]-duration (i.e. normalised values for the acoustic duration of /1\#\#/ and the normalised TTC-Dur values for phrase-medial /1/-realisations), as represented here in Figure 6. 

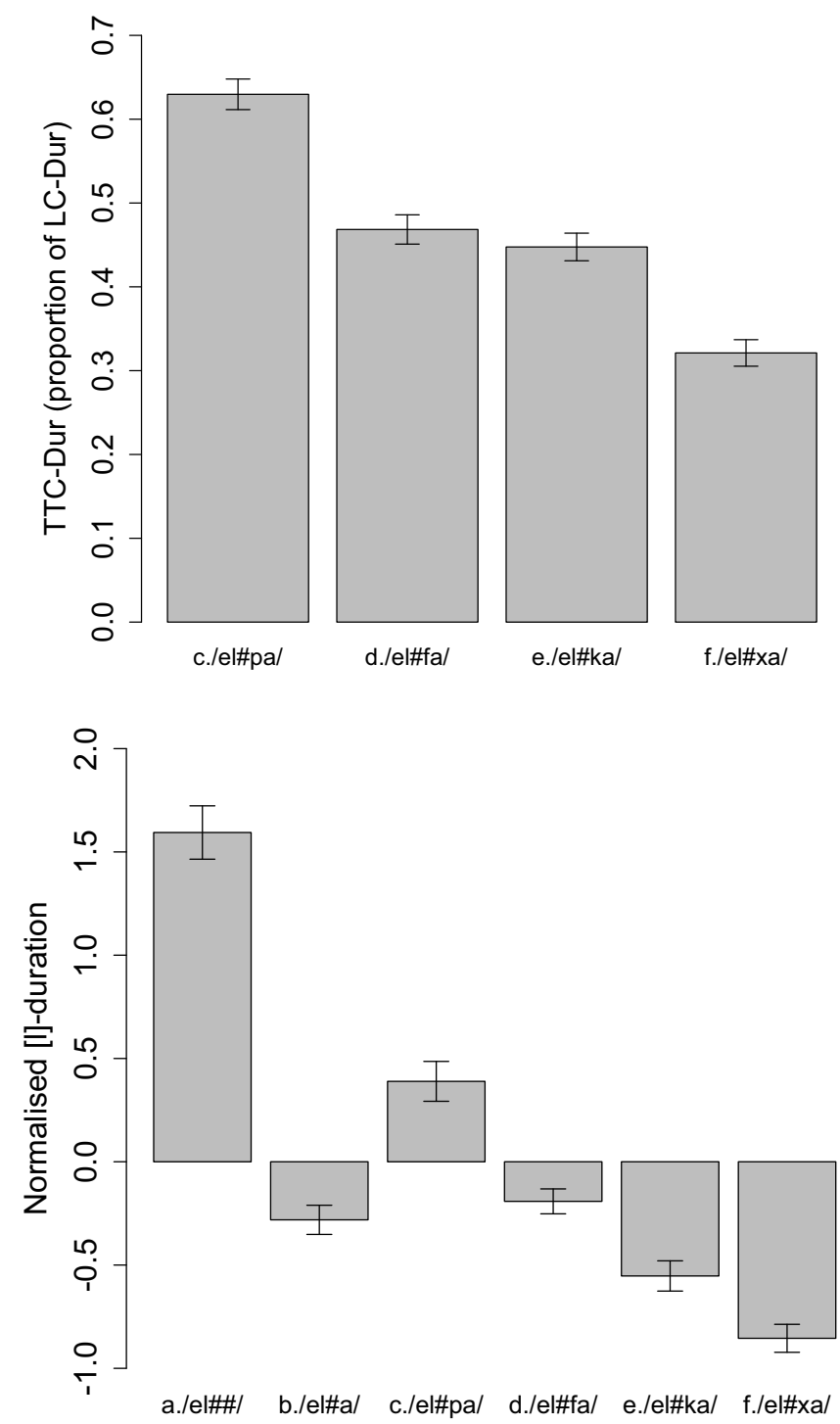

Figure 6 TTC-Dur in /1\#C/ contexts as a percentage of /1\#C/-Dur (upper panel). Normalised [1]-duration values calculated on acoustic duration for prepausal /1\#\#/ and TTC-Dur values for phrase-medial/1/-realisations (lower panel). Error bars show $95 \%$ confidence intervals.

\subsection{EPG measurements}

Figure 7 shows palatograms extracted at the point of maximal contact from typical /1/realisations for each of the speakers in contexts (a)-(f), as listed in Table 1. In agreement with the durational generalisations discussed above, there is clear evidence of reduction in these data, i.e. in the degree of linguo-palatal contact across test contexts. Observe, firstly, that contact in the anterior region of the palate is most robust in /1\#\#/-realisations. In this environment, there is activation of electrodes in rows 1-3 for all speakers and full contact across the centre of the palate. Although the locus of contact is less anterior, complete central contact also occurs in the $/ 1 \mathrm{H} /$ context. Elsewhere, the electrodes in row 1 are generally 
S1

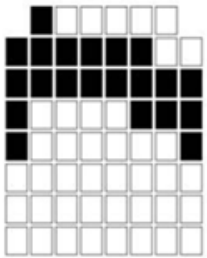

b. /-pel\#a-/

c. /-pel\#pa-/

d. /-pel\#fa-/

e. /-pel\#ka-/
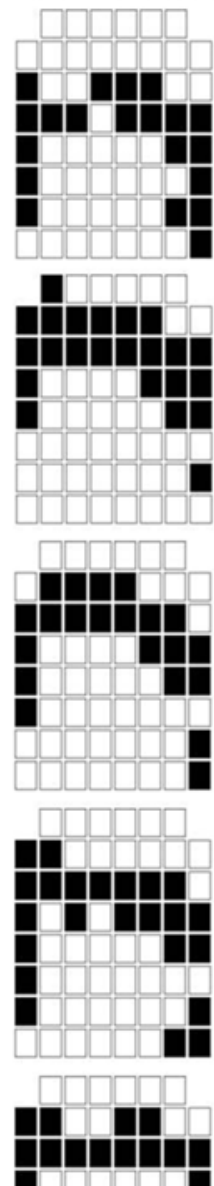

f. /-pel\#xa-/

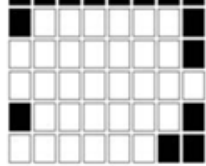

$\mathrm{S} 2$
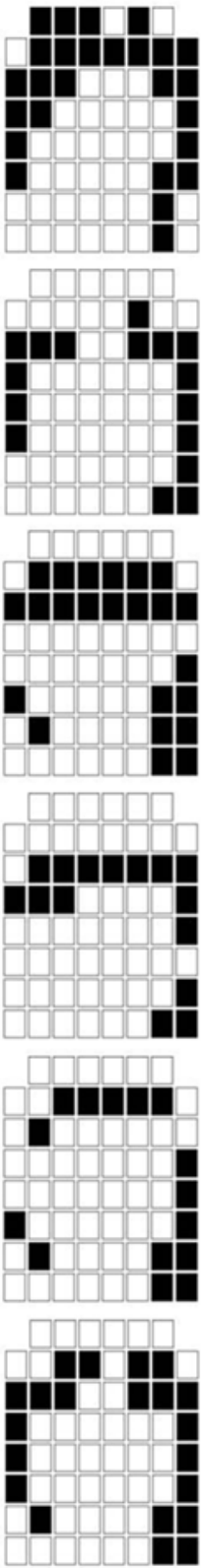

S3
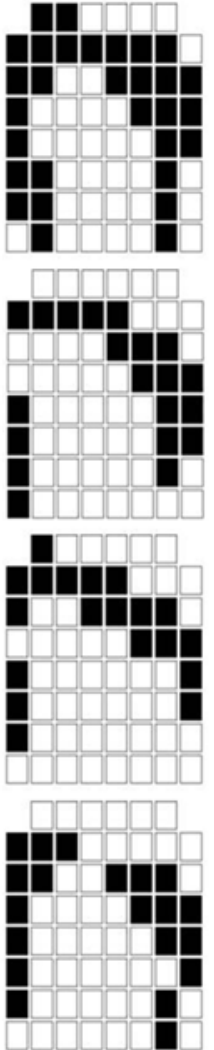

101
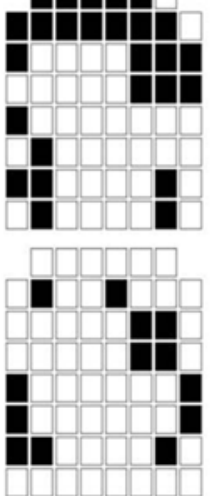

S4
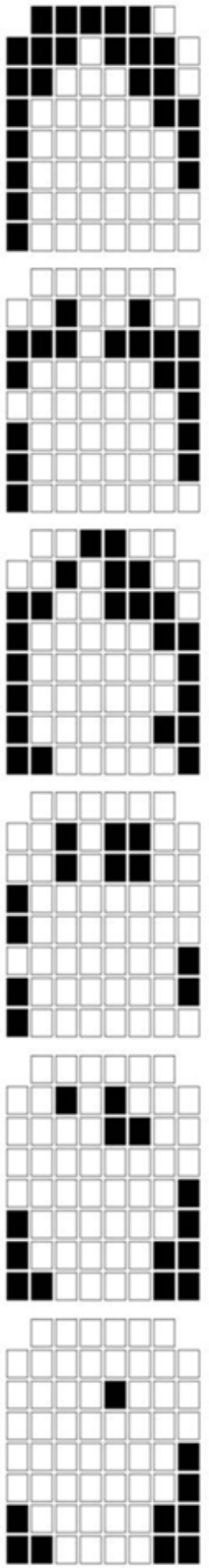

Figure 7 Palatograms extracted from typical /1/-realisations at the point of maximal contact. The nonce words from which these examples are taken all end in a final /-pel/ sequence.

not activated in other phrase-medial /1/-realisations. One exception to this the $/ 1 \mathrm{Hk} /$ realisation shown for S3. In addition, reduction in central contact can be observed in a number of these tokens, particularly in /1\#a/ (S2 and S4), /1\#f/ (S3 and S4), /1\#k/ (S4) and /1\#x/ (S2, S3 and S4). The following sections explore these patterns in greater detail on the basis of APC measurements (Section 3.2.1) and PPC measurements (Section 3.2.2). 


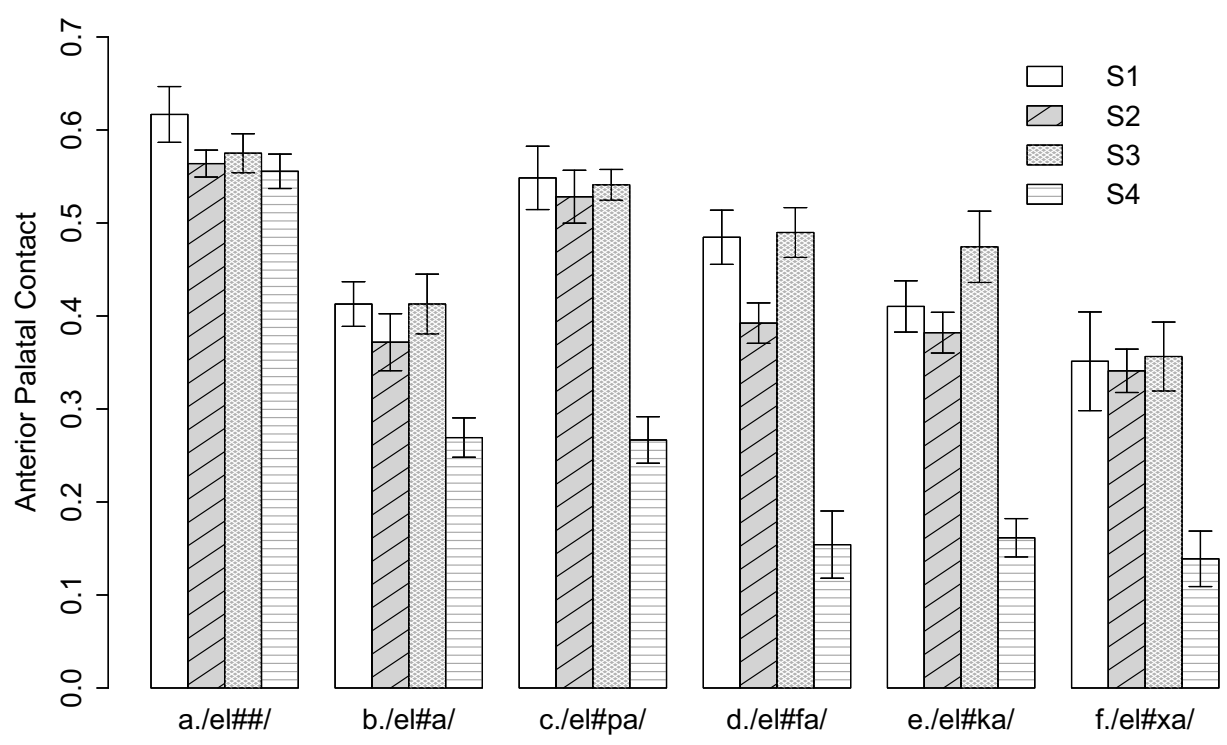

Figure 8 Anterior Palatal Contact measurements. Error bars show 95\% confidence intervals.

\subsubsection{Anterior Palatal Contact}

Figure 8 shows mean values for APC in each test environment for the four speakers (numerical values are listed in Appendix C). First and foremost, the visualisation of the data confirms the impressionistic observation stated above that prepausal /1/ has the greatest amount of linguo-alveolar contact for all speakers. Mean APC values here indicate that more than half of the electrodes within the APC zone are activated on average in /1\#\#/-realisations. This contrasts with word-final prevocalic/1/-realisations in which tongue-tip contact is highly reduced: mean APC values in the $/ 1 \mathrm{Ha} /$ environment are at least 30\% lower for speakers $\mathrm{S} 1, \mathrm{~S} 2$ and $\mathrm{S} 3$ than for the /1\#\#/ environment; and for speaker S4, the mean APC value for word-final prepausal $/ 1 /$ is more than double that of word-final prevocalic $/ 1 /$.

As also already noted, /1/ preceding /p/ is articulated with comparably high levels of linguo-alveolar contact for S1, S2 and S3. In comparison with /1\#\#/-realisations, contact in $/ 1 \mathrm{Ap} /$ is approximately $7 \%$ lower for $\mathrm{S} 1$, but only 3\% lower for $\mathrm{S} 2$ and $4 \%$ lower for $\mathrm{S} 3$. Moreover, the data from these three speakers display a progressive decline in APC across contexts (d)-(f). This indicates that tongue-tip contact for $/ \mathbf{l} /$ before $/ \mathrm{f} /$ is somewhat less robust than in the $/ 1 \# \mathrm{p} /$ context, and the $/ 1 /$-realisations are even less occluded preceding the dorsal consonants, $/ \mathrm{k} /$ and $/ \mathrm{x} /$. This pattern holds largely for speaker $\mathrm{S} 4$ too. Whereas $\mathrm{S} 4$ shows a more dramatic reduction in all phrase-medial /1/-realisations (when compared to the relatively high level of contact registered in /1\#\#/-realisations produced by this speaker), contact in $/ \mathrm{l} \# \mathrm{p} /$ is approximately $11 \%$ greater, on average, than in $/ 1 \mathrm{H} /$. Contact in $/ 1 \mathrm{H} \mathrm{x} /$, by contrast, is only mildly reduced relative to $/ \mathrm{l} \# \mathrm{k} /$ (a difference of only $c .2 \%$ in this case). Interestingly, S4 is the only speaker for whom the majority of preconsonantal $/ 1 /$-realisations have markedly less tongue tip contact on average than prevocalic /1/-realisations.

A number of general trends are confirmed by mixed-effects regression analysis on the APC data. Table 2 lists the fixed effects in the APC model, as described in Section 2.3 above, on the basis of pooled values for all speakers. Strong significance values obtain for all levels of Context where $/ \mathrm{l} \#$ / is the reference level. This confirms the fact that tongue contact in /1\#\#/-realisations is significantly greater than in all other contexts. Post-hoc testing

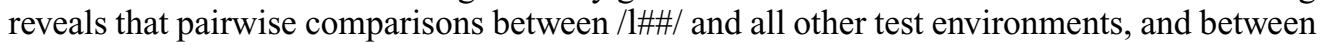
$/ \mathrm{l} \mathrm{p} /$ and all other environments, achieve significance at least at the 0.05 level. Comparisons between the following contexts are non-significant (i.e. $p>.1$ in each case): / $/ \# \mathrm{a} / \sim / \mathbf{l} \# \mathbf{f} /$ 
Table 2 Summary of fixed effects in the APC model.

\begin{tabular}{|c|c|c|c|c|c|}
\hline & Estimate & Std. Error & df & $t$-value & $p$-value \\
\hline (Intercept) & 0.572 & 0.0432 & 3.751 & 13.229 & $<.001$ \\
\hline /1\#a/ & -0.220 & 0.0239 & 198.768 & -9.218 & $<.001$ \\
\hline /l\#f/ & -0.199 & 0.0244 & 212.377 & -8.138 & $<.001$ \\
\hline$/ \mathrm{l} \# \mathrm{k} /$ & -0.211 & 0.0237 & 196.564 & -8.891 & $<.001$ \\
\hline$/ 1 \# \mathrm{p} /$ & -0.130 & 0.0243 & 193.866 & -5.345 & $<.001$ \\
\hline$/ 1 \# \mathrm{x} /$ & -0.243 & 0.0240 & 188.735 & -10.109 & $<.001$ \\
\hline
\end{tabular}

$(t=-1.135), / 1 \# \mathrm{a} / \sim / 1 \# \mathrm{k} /(t=-0.489), / 1 \# \mathrm{a} / \sim / 1 \# \mathrm{x} /(t=1.187), / 1 \# \mathrm{f} / \sim / 1 \# \mathrm{k} /(t=0.625)$, $/ \mathrm{l} \# \mathrm{f} / \sim / \mathrm{l} \mathrm{\#} /(t=2.221)$ and $/ \mathrm{l} \# \mathrm{k} / \sim / 1 \mathrm{Hx} /(t=1.716)$.

From these results, it is clear that both the place and stricture targets of following segments exert a coarticulatory influence on magnitude of tongue-tip contact in a preceding $/ 1 /$-realisation. In the context of a following phrase boundary, tongue-tip occlusion is maximal: in none of the phrase-medial contexts tested in this experiment does $/ 1 /$ exhibit more robust linguo-alveolar contact than in absolute phrase-final position. By contrast, /1/ is relatively reduced for all speakers when followed by a plosive, and the reductive effect is more extreme in $/ 1 \mathrm{Hk} /$-sequences than in $/ \mathrm{l} \# \mathrm{p} /$-sequences. Interestingly, tongue contact in the $/ \mathrm{l} \# \mathrm{p} /$ environment is greater than in $/ 1 \# \mathrm{f} /(t=-3.406, p=.012)$ and $/ \mathrm{l} \mathrm{Ha} /(t=-4.545, p>.001)$ environments. Thus, these precontinuant $/ 1 /$-realisations exhibit significant reduction in alveolar contact when compared to $/ 1 /$ before $/ \mathrm{p} /$. The same tendency is noted at the velar place of articulation. More specifically, Figure 8 reveals that tongue tip contact in $/ 1 \# \mathrm{x} /$-realisations is more reduced than $/ \mathrm{l} /$ before $/ \mathrm{a} /$ or $/ \mathrm{k} /$ for all speakers. However, whilst contact in $/ \mathrm{l} \# \mathrm{k} /$ is significantly reduced relative to contact in $/ \mathrm{l} \mathrm{p} /(t=-3.957, p=.002)$, differences in the degree of reduction in $/ \mathrm{l} \mathrm{Ha} /, / 1 \mathrm{Hk} /$ and $/ 1 \mathrm{H} \mathrm{x} /$-realisations are overall not sufficiently robust to reach statistical significance.

\subsubsection{Posterior Palatal Contact}

In comparison to the high variability of anterior contact observed across the different test environments, contact in the posterior region of the palate generally displays more minor variation (see Figure 9).

Nevertheless, inspection of these data does reveal important trends. Firstly, /1\#\#/realisations have less contact in the posterior region of the palate that word-final prevocalic /1/-realisations for all speakers except S4. This contrasts to the APC data which show the highest level of contact in /1\#\#/. Thus, whereas prevocalic /1/ displays significantly less tongue-tip contact than prepausal $/ 1 /$, the presence of a following vowel produces a mild increase in dorsal contact for three of the speakers. Secondly, observe that preplosive /1/-realisations display greater posterior contact than the corresponding precontinuant $/ 1 /$-realisations, both at the labial and velar places of articulation. This effect is most robust for S3, for whom posterior contact in $/ \mathrm{l} \# \mathrm{p} /$ is approximately $5 \%$ greater than in $/ 1 \mathrm{HF} /$, and contact in $/ \mathrm{l} \# \mathrm{k} /$ exceeds contact in $/ \mathrm{l} \mathrm{H} /$ by $c .11 \%$.

Across places of articulation, differences can also be observed in the data. For example, again for $\mathrm{S} 3$, posterior contact is approximately $15 \%$ greater in $/ 1 \mathrm{Hk} /$ than in $/ 1 \mathrm{Hp} /$. This difference is also reasonably high for $\mathrm{S} 4($ c. $9 \%)$. However, posterior contact in $/ \mathrm{l} \# \mathrm{k} /$ is only marginally greater than in $/ 1 \mathrm{\# p} /$ for S2 $(<1 \%)$, and this difference is also relatively small for $\mathrm{S} 1$ (c. 3.5\%). Consequently, this indicates that the a following dorsal stop seems to produce a stronger coarticulatory effect of the preceding /1/ for S3 and S4 than it does for S1 and S2.

The mixed-effects regression model for PPC measurements summarised in Table 3 again confirms a number of these points. Firstly, posterior contact in $/ 1 \# \# /$ is significantly less robust than in all other test environments except $/ \mathrm{l} \# \mathrm{f} /$. As expected, contact is greatest $/ \mathrm{l} \# \mathrm{k} /$, but also relatively high in $/ 1 \mathrm{Ha} /$. Whilst increased dorsal contact in $/ 1 \mathrm{Ha} /($ relative to $/ \mathrm{l \# \# /)} \mathrm{might}$ 
Table 3 Summary of fixed effects in the PPC model.

\begin{tabular}{lccrrc}
\hline & Estimate & Std. Error & \multicolumn{1}{c}{$\mathrm{df}$} & $t$-value & $p$-value \\
\hline (Intercept) & 0.182 & 0.0160 & 6.572 & 11.325 & $<.001$ \\
/1\#a/ & 0.053 & 0.0144 & 255.543 & 3.682 & $<.001$ \\
//\#f/ & 0.012 & 0.0148 & 251.167 & 0.835 & $>.1$ \\
/1\#k/ & 0.119 & 0.0143 & 263.004 & 8.343 & $<.001$ \\
//\#p/ & 0.046 & 0.0145 & 252.047 & 3.133 & $<.01$ \\
//\#x/ & 0.047 & 0.0144 & 259.149 & 3.279 & $<.01$ \\
\hline
\end{tabular}

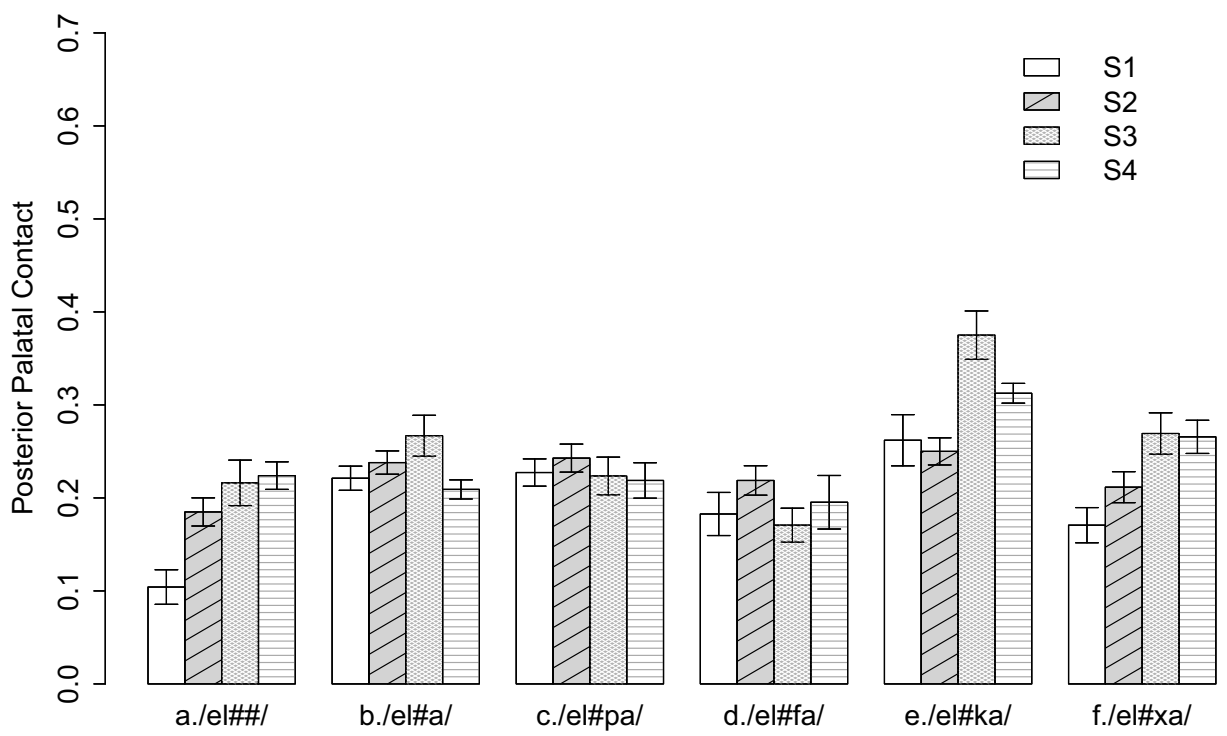

Figure 9 Posterior Palatal Contact measurements. Error bars show 95\% confidence intervals.

be expected due to the occurrence of a following vowel (the articulatory profile of which necessarily involves its own tongue-dorsum target), increased dorso-palatal contact in $/ 1 \mathrm{Hp} /$ is perhaps less expected. A probable source of this variation is the use of a more anterior closure location in prepausal $/ 1 /$ than in $/ 1 \# \mathrm{p} /$. Although $/ 1 /$-realisations in both of these contexts are characterised by high levels of anterior contact, $/ 1 /$-articulation in $/ 1 \# \mathrm{p} /$, as already mentioned, typically activates electrodes in row 2 and beyond (see Figure 7). The more retracted locus of closure in $/ \mathrm{l} \# \mathrm{p} /$ therefore simultaneously causes greater activation of posterior electrodes than $/ 1 \# \# /$-articulations, in which the locus of articulation is more advanced (i.e. typically activating electrodes in row 1 ).

Regarding predorsal $/ 1 /$ realisations, post-hoc tests indicate that all pairwise comparisons

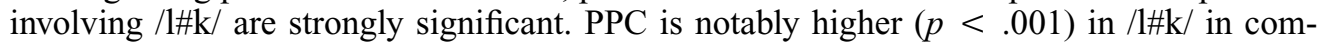
parison to $/ \mathrm{l} \# \# /(t=-8.308), / 1 \mathrm{Aa} /(t=-4.769)$, and $/ \mathrm{l} \# \mathrm{x} /(t=-5.196)$. This confirms the pattern illustrated in Figure 9, namely that posterior contact during /1/ is greatest preceding $/ \mathrm{k} /$. However, dorsal contact in $/ \mathrm{l} \# \mathrm{x} /$ is not significantly different from that in $/ \mathrm{l} \mathrm{Aa} /(t=0.407$, $p>.01)$. Yet other comparisons confirm further effects of interest. In comparison to phrasefinal prepausal $/ 1 /$, dorsal contact is quite a bit higher in phrase-medial prevocalic $/ 1 /(t=$ $-3.661, p=.005)$ and also somewhat more robust in $/ 1 \mathrm{H} \mathrm{x} /(t=-3.265, p=.012)$.

In sum, these results confirm that dorso-palatal contact in $/ \mathrm{l} \mathrm{C} /$-realisations varies significantly across test contexts, and to some extent, across speakers. PPC measurements indicate 
that $\mathrm{S} 3$ and $\mathrm{S} 4$ permit greater coarticulation in $/ \mathrm{H} \mathrm{C} /$-sequences than $\mathrm{S} 1$ or $\mathrm{S} 2$ : that is, tonguetip and tongue-dorsum gestures overlap during the $/ 1 /$ itself somewhat less extensively for $\mathrm{S} 1$ and much less extensively for S2. In general, analysis of the PPC data indicates that the presence of a following dorsal consonant or the vowel /a/ causes significant increase in dorso-palatal contact during the articulatory realisation of following $/ 1 /$.

\subsection{Summary of results}

The foregoing analysis confirms that there are significant patterns of spacial and temporal reduction of word-final /1/ in Spanish in different phonotactic environments. In general, reduction is more extreme before dorsal obstruents than before labial ones. Furthermore, word-final /1/-realisations before fricatives tend to display less linguo-palatal contact and shorter contact duration than when $/ 1 /$ is followed by a stop. In addition to the general patterns that emerge from the data, there is also evidence for idiosyncratic reduction patterns. Thus, although all speakers exhibit a tendency to produce stronger or weaker /1/-realisations depending upon the segmental environment in which it occurs, there is clear inter-speaker variation in the degree of reduction that $/ 1 /$ undergoes across contexts.

\section{Discussion}

The results reported above raise questions of both a phonetic and phonological nature about /1/ in Spanish. This section focuses on two issues in particular, namely (i) the syllabification of word-final / 1 / in prevocalic environments, and (ii) the role of coarticulation in the reduction patterns of word-final $/ 1 /$.

\subsection{Syllabification of word-final /l/ in Spanish}

With regard to articulatory magnitude, the results of this study permit two key generalisations to be drawn. Firstly, word-final /1/ has the greatest amount of linguo-palatal contact in phrase-final coda position; and secondly, magnitude of contact is significantly reduced in phrase-medial coda positions (i.e. preconsonantally) and in phrase-medial position before a following vowel-initial word. In view of this, it is fitting to consider how the articulatory data can shed light on the question of whether word-final consonants are targets for phrasal resyllabification in Spanish.

Under the assumption that word-final /1/ is a target for resyllabification before vowelinitial words, it is important to consider why realisations of resyllabified /1/ should display articulatory reduction in such a consistent manner. This is particularly relevant since syllabifying /-Vl\#V-/ sequences as [-V.lV-] causes changes not only at the syllable level but also at higher-level prosodic structure (see Byrd et al. 2005: 3861). Thus, phonological word-final $/ 1 /$ in e.g. $[\omega[\sigma-\mathrm{Vl}]][\omega[\sigma \mathrm{V}-]]$ reprosodifies to word-initial position under any resyllabification process that enforces coda capture: i.e. $\rightarrow[\omega[\sigma-V]][\omega[\sigma \mathrm{lV}-]]$. The fact that putative resyllabified /1/ occupies these domain-initial positions is not trivial.

Other articulatory studies (mainly on English) have shown that consonants are produced with longer durations, greater displacement of articulators and greater contact between articulators when they occur, for example, in word-initial onsets than when they occur in coda position (e.g. Byrd 1996, Fougeron \& Keating 1997, Byrd et al. 2005). EPG data reported in Keating, Wright \& Zhang (1999) are of particular relevance here. In this study, the high level of linguo-palatal contact that characterises English utterance-initial /1/-realisations differs only minimally from utterance-final word-initial $/ 1 /$. However, contact in utterance-initial word-final $/ 1 /$ is vastly reduced. With regard to the Spanish data, as discussed above, wordfinal prevocalic / $1 /$ is consistently more reduced - both in spacial and durational terms than in preconsonantal contexts like $/ 1 \mathrm{H} /$ and in phrase-final contexts (i.e. /1\#\#/) where /1/ 
is in canonical coda position. Although caution must be exercised in attempting to generalise across languages, the current data do suggest that word-final prevocalic /1/ may not be a target for the sort of strengthening operation that has been documented for (non-derived) word-initial consonants in other languages.

The question then arises of whether word-final / / should rightfully be considered a target for resyllabification across word boundaries. An alternative analysis assuming that wordfinal prevocalic $/ 1 /$ remains in the coda in $/-1 \mathrm{HV}-/$ sequences does not offer insights into why phrase-final and some preconsonantal /1/-realisations should display significantly greater contact than word-final prevocalic /1/-realisations. Moreover, attempting to pursue an explanation of the articulatory patterns assuming an ambisyllabification analysis is problematic for Spanish. Observing apparent exceptional behaviour of certain consonants in intervocalic contexts (principally in English), phonologists have sometimes proposed analyses based on ambisyllabicity under which a consonant is simultaneously linked to the coda node of one syllable and the onset node of a following syllable. Most relevant for the present discussion is the type of ONSET AMBISYLLABIFICATION that Rubach (1996: 222) proposes for the analysis of English word-final prevocalic /1/. Here, in having a dual link to coda and onset nodes, word-final prevocalic /1/-realisations are permitted to have a special realisation that involves overriding the general phonological requirement for word-final /1/ to be dark (see Jensen 2000 and Scobbie \& Pouplier 2010 for further discussion).

However, unlike English, no dialect of Spanish exhibits contextual allophonic variation between [1] and [1]: /1/ is light both in onset and coda position. As reported above, linguo-palatal contact in canonical coda $/ 1 /$ is often very robust, and there is no evidence that $/ 1 /$ is a regular target for any sort of vocalisation process in the speech of the Peninsular speakers reported on here in any coda context. Although word-initial /1/-realisations were not tested in the experiment, it seems unlikely that canonical onset $/ 1 /$-realisations would display significantly greater displacement of articulators or fuller contact patterns than the coda realisations of $/ 1 /$. An ambisyllabification analysis under which word-final prevocalic $/ 1 /$ realisations might show higher degrees of reduction because they have an intermediate realisation between a prototypically strong onset / $1 /$ and a prototypically weaker coda $/ 1 /$ is therefore not tenable for Spanish.

The conclusion here is that $/ 1 /$-reduction does not provide particularly strong evidence for phrasal resyllabification of the type $/-\mathrm{Vl} \# \mathrm{~V}-/ \rightarrow[-\mathrm{V} .1 \mathrm{~V}-]$ in Spanish; and neither does the assumption of the operation of such a process allow for specific predictions to be made about the degree of articulatory reduction of word-final $/ 1 /$ in phrasal prevocalic contexts. I now turn to consider another avenue of explanation for the observed patterns, namely how phonotactics may affect the reduction of word-final $/ 1 /$.

\subsection{The role of coarticulation}

Since predictions based on different prosodificiations of word-final /1/ do not square neatly with the articulatory data, this section considers an alternative line of explanation for the observed reduction patterns that does not rely on phonological structural factors. It is argued that coarticulation, or gradient overlap of contiguous articulatory targets in the production of fluent speech, is the most significant factor for determining the degree of reduction of word-final / $1 /$ across contexts.

As alluded to in Section 1, an important finding of previous research on $/ 1 /$ is that laterals can exert quite substantial coarticulatory effects on preceding vowels. For example, Recasens et al. (1997) report that the dorsum retraction gesture in dark /1/-realisations in Catalan is strongly coarticulated with preceding vowels, whereas the coarticulatory effect on following vowels is less robust. By contrast, EPG data from German speakers show that the location of the alveolar closure in light /1/-realisations is quite stable across different vowel contexts (Recasens, Fontdevila \& Pallarès 1996: 181). This is to say that German light /1/ displays no significant tendency to have a more fronted realisation in front-vowel contexts like /ili/, nor a 
significantly more retracted realisation in back-vowel contexts like /ulu/. Whilst the present study did not aim to test the coarticulatory effects of /1/ upon flanking vowels, the finding that /1/ may display some resistance to the coarticulatory influence of surrounding segments is significant. In this connection, Recasens et al. (1996: 181) also point out that both German light /1/ and Catalan dark /1/ exhibit less sensitivity to vowel coarticulation than other segments like /n/ (and also Catalan /r/, see Recasens et al. 1996: 169, reporting on Recasens 1991). Similarly, Proctor's (2011) ultrasound study on the realisation of liquid consonants shows that intervocalic /1/ in Spanish displays higher resistance to V-to-C coarticulation than intervocalic /d/, particularly with regard to the tongue-dorsum target (see also Proctor 2009: $\S 4)$. Note here that $/ \mathrm{d} /$ is a target for an extensively studied phonological process of intervocalic spirantisation (Navarro Tomás 1957: §75; Harris 1969: §2.5.1; Martínez-Celdrán 1991; Mascaró 1991; Hualde 2014: §7.2.2) which results in high levels of articulatory reduction, i.e. to [ð], approximated [ð]], or even zero. However, reduction in $/ 1 /$ - at least to the extent that this can be reliably observed on the basis of midsagittal images (see Proctor 2011: 474-475) - may be better characterised as a variable, gradient phenomenon that affects tongue-tip constriction targets to a greater level than tongue-dorsum targets.

Whereas in languages like German, /1/ may resist horizontal coarticulation - i.e. the forward or backward pull of surrounding vowels on the location of the articulatory closure - the articulatory demands that following segments place on the oral articulators produce strong coarticulatory effects along the vertical dimension on preceding /1/-realisations in Spanish. Crucially, the degree of reduction that $/ 1 /$ undergoes is dependent on the extent to which the articulatory targets of following segments interfere with the articulatory configuration of $/ 1 /$. Realisations of word-final /1/ produced by all speakers in this study, for example, are significantly shorter in the context of word-initial $/ \mathrm{k} /$ than a word-initial $/ \mathrm{p} /$ (see Section 3.2.1). Significant effects of place of articulation on the magnitude of contact were also observed in the anterior contact zone (for S2 and S4) and the posterior contact zone (for S3 and S4). This situation plausibly arises because of what Recasens et al. term GESTURAL ANTAGONISM: that is, realisation of the dorso-velar gesture for $/ \mathrm{k} /$ produces a reductive effect on apico-alveolar gesture of the preceding / $1 /$. The precise outcome of this articulatory conflict is speaker specific. This confirms that some speakers (e.g. S1) control or correct for the coarticulatory effect of $/ \mathrm{k} /$ more actively than others (e.g. S4). By contrast, the labial closure for $/ \mathrm{p} /$ poses no gestural conflict for the preceding $/ 1 /: / 1 /$ therefore displays significantly longer duration and more robust linguo-palatal contact in $/ \mathrm{l} \# \mathrm{p} /$ clusters compared to $/ \mathrm{l} \# \mathrm{k} /$ clusters. ${ }^{11}$

In addition, the current results provide evidence that word-initial fricatives cause more dramatic articulatory reduction of preceding word-final $/ 1 /$ than word-initial stops. This occurs at both places of articulation tested in the experiment: /1/ shows a tendency to be more reduced, both in spacial and temporal terms, in the context of following /f/ than following $/ \mathrm{p} /$, and in the context of following $/ \mathrm{x} /$ than following $/ \mathrm{k} /$. In addition to gestural antagonism, this finding suggests that aerodynamic antagonism also plays a role in determining the degree of reduction of $/ 1 /$. Existing research on the articulation of voiceless fricatives has shown that devoicing gestures (i.e. glottal abduction) involve greater displacement of the vocal folds and are initiated much earlier in vowel+fricative contexts than in vowel+stop contexts. Hence, the articulation of voiceless fricatives involves more anticipatory devoicing than the articulation of voiceless stops. As noted by Hoole (1999: 108ff.) and Gobl \& Ní Chasaide (1999:

\footnotetext{
${ }^{11}$ An anonymous reviewer points out $/ 1 /$ and $/ \mathrm{k} /$ gestures may also display a degree of 'gestural compatibility' in the dorsal region, i.e. tongue-body retraction for articulation of $/ 1 /$ need not be antagonistic to the dorsal gesture for $/ \mathrm{k} /$. In this sense, speakers may produce $/ \mathrm{l} /$ with a lowered tongue position in $/ \mathrm{l} \# \mathrm{k} /$ relative to a potentially higher position in e.g. /l\#t/. Precisely how speakers negotiate conflicting articulatory demands of this sort is not something that can be examined with EPG. Alternative imaging techniques that allow for tongue-body positioning to be tracked and compared (e.g. ultrasound imaging) would be necessary to address this question.
} 
$131 \mathrm{ff}$.), this is a consequence of the specific aerodynamic conditions necessary for the generation of robust frication which can only be achieved by precise articulator control (Solé 2003: 2761; 2010: 291).

It is possible, therefore, that aerodynamically motivated anticipation of the articulatory gestures associated with voiceless fricatives is responsible for the tendency for $/ 1 /$ in $/ 1 \mathrm{Hf} /$ and $/ \mathrm{H} \mathrm{x} /$ sequences to be more extensively reduced than in $/ \mathrm{l} \mathrm{Hp} /$ and $/ \mathrm{l} \# \mathrm{k} /$ sequences. $^{12}$ Whilst this effect is marginal in $/ \mathrm{l} \# \mathrm{k} / \mathrm{vs} / \mathrm{l} \# \mathrm{x} /$ sequences, a particularly striking finding is that $/ 1 /$ is significantly shorter and has less anterior contact in $/ 1 \mathrm{Hf} /$ sequences than in $/ \mathrm{l} \# \mathrm{p} /$ sequences. This effect is observed for all speakers but it is strongest for S2 and S4 (see Sections 3.1 and 3.2.1). For these speakers, it is clear that articulation of word-initial fricative exerts a significantly greater reductive effect upon preceding word-final /1/ than a word-initial stop even when neither of the word-initial consonants involves the realisation of a lingual occlusion target. This suggests that articulatory settings necessary to achieve the required levels of intraoral pressure for the realisation of /f/ impose, to some extent, an antagonistic effect upon the realisation of the preceding $/ 1 /{ }^{13}$ The palatograms in Figure $7(\mathrm{c}-\mathrm{d})$ show that contact in the anterior region of the palate is observably lower in $/ \mathrm{l} \mathrm{H} /$ tokens in comparison to $/ \mathrm{l} \mathrm{p} /$ tokens for S2 and S4; and the consistency of this effect is reflected in the substantial difference in APC measurements in these environments for these speakers. However, given that this effect is more minor for S1 and S3, it also appears to be the case, much like speakerspecific correction strategies for antagonistic gestural effects, that different speakers may show greater or lesser tendencies to correct for aerodynamic conflict in $/ \mathrm{l} \mathrm{HC} /$ sequences. This supports the generalisation that 'articulatory strategies and associated aerodynamic effects may vary from subject to subject' (Solé 2010: 301).

With regard to the coarticulatory factors at play in $/-\mathrm{Vl} \# \mathrm{~V}-/$ sequences, it is likely that the general trend for $/ 1 /$ to undergo extensive reduction in word-final prevocalic position (relative to word-final prepausal position) arises from a V-to-C coarticulation effect. Recall that the vowel context used for testing word-final prevocalic /1/ was /-el\#a-/. Here, the wordinitial /a/, although unstressed, probably contributes quite a significant reductive force to the relaxation of the preceding /1/, especially in the anterior alveolar region. Although the EPG measurements used in this study do not permit fine-grained quantification of the relative anteriority of tongue tip placement across /1/-realisations, it can be seen from visual inspection of the palatograms in Figure 7 that electrodes in the frontmost two rows are activated at contact maxima in /1\#\#/ tokens for all speakers. By contrast, contact is greatest in rows 2 and $3 \mathrm{in} / \mathrm{l} \mathrm{\# a} /$ tokens. Impressionistically, it therefore seems plausible that tongue-root retraction for articulation of /a/ may cause undershoot of the tongue-tip target associated with the preceding 1/. Although this hypothesis is in disagreement with the results from German light /1/realisations reported on in Recasens et al. (1998), it is in agreement with previous articulatory work on Spanish (Martínez Celdrán \& Fernández Planas 2007: 134ff.) and, more generally, with the predictions of the DEGREE OF ARTICULATORY CONSTRAINT (DAC) model of coarticulation (Recasens et al. 1997, 1998). Specifically, segments that produce anticipatory coarticulatory effects on preceding segments are expected to produce only relatively minor

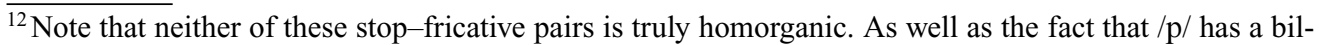
abial realisation and /f/ a labiodental one, articulation of $/ \mathrm{x} /$ in Spanish is thought to involve a more uvular constriction in comparison to velar / $\mathrm{k}$ / (Honorof 1999: 15). It is therefore possible that the differences in place-of-articulation between the voiceless stops and the phonologically corresponding voiceless fricatives may contribute something to the trend for $/ 1 /$ to be more reduced before $/ \mathrm{f} /$ and $/ \mathrm{x} /$ than before $/ \mathrm{p} /$ and $/ \mathrm{k} /$. This issue is not something that can be investigated using EPG: additional research using other articulatory imaging techniques is necessary to confirm this.

${ }^{13}$ An anonymous reviewer also points out that maintaining a steady airstream for production of [f] may also require some manipulation of the tongue (e.g. for directing the air current). If this is the case, this process may also contribute to the antagonistic effect of /f/ upon a preceding /1/.
} 
carry-over coarticulatory effects on following segments, if any at all. Moreover, segments that cause only negligible amounts of carry-over coarticulation are predicted in turn to be more highly susceptible to the coarticulatory influence of following segments. Whilst the relative direction of coarticulatory effects exerted by /1/ upon preceding and following segments was not examined in this study, the second prediction of the DAC model is borne out by the current data: that is, that word-final prevocalic /1/ consistently displays some effects of spacial and temporal reduction which are most readily attributable to coarticulation with following segments.

The results of the present study therefore show commonalities with existing research on assimilation in Spanish. As noted in Section 1 above, previous EPG studies have found evidence that syllable-final nasals sometimes assimilate categorically to following stops (e.g. Kochetov \& Colantoni 2011b). However, there is also evidence of coarticulatory gradience in Spanish NC-realisations, for example in nasal+continuant sequences in Kochetov \& Colantoni's data. Gradient patterns have also been shown to interact with general speakerspecific articulation trends in studies on nasal assimilation in Spanish (Ramsammy 2012), and likewise in other languages. As the present results demonstrate, the coarticulatory behaviour of word-final $/ 1 /$ in Spanish also depends on the place and stricture targets of following sounds, and is sensitive to individual speaker variation.

Relatedly, some factors that almost certainly also affect the degree of reduction of $/ 1 /$ in different phonetic contexts were not examined in this study. For example, the present study was designed to test the realisation of word-final $/ 1 /$ in a variety of phonological contexts. Accordingly, data from word-initial, and particularly phrase-initial /1/, was not recorded. In light of the finding that word-final prevocalic /1/ exhibits effects of contextual weakening, it would be beneficial to be able to compare $/ 1 /$ in putative word-final resyllabification contexts to /1/-realisations in canonical onset environments (including word-medially). Similarly, speech rate was not controlled for in the experimental work. It is possible that different degrees of reduction might have been observed had the speakers been recorded producing utterances in a slow and careful speech style vs a quicker, informal style, for example. As shown in the analysis of the durational data, /1/-realisations produced by S4 are typically shorter than those produced by the other speakers; and this speaker also has the greatest amount of reduction in the front region of the palate, but not in the posterior region. Although speech-rate measures were not extracted from the data, impressionistically it seems to be the case the S4 may have adopted a slightly faster speech rate that the other participants. In a study of this nature, this could be attributable to individual differences in typical speech rate, and it is also possible that speakers may have reacted differently to the nonce stimuli and variable carrier phrases used in the experiment. Investigating the extent to which real-word items may show similar or distinct patterns from those reported on here, and whether effects of lexical and phonotactic frequency also contribute in some significant way to reduction patterns, is therefore an outstanding goal for future research on articulatory reduction in Spanish. More generally, research on the effect of speech rate on assimilation patterns in Spanish also remains to be undertaken.

\section{Conclusion}

This study set out to test to what extent word-final /1/ in Spanish is sensitive to reduction - or ARTICULATORY RELAXATION - in different phonotactic environments. In preconsonantal contexts, significant effects of place and manner of following word-initial consonants were observed. Linguo-palatal contact is shorter and of lesser magnitude when word-final /1/ occurs before word-initial fricatives than word-initial stops; and word-initial consonants requiring the formation of lingual occlusion targets (i.e. $/ \mathrm{k} /$ and $/ \mathrm{x} /$ ) have a greater reductive effect upon preceding word-final /1/ than word-initial consonants in which active tongue gestures are not involved (i.e /p/ and /f/). Furthermore, /1/ is significantly more reduced, both 
in spatial and durational terms, in phrase-medial prevocalic contexts (i.e. /-Vl\#V-/) than in phrase-final coda position. Whilst these tendencies were observed for all speakers, significant speaker-specific effects were also observed. This finding is in agreement with the results of other articulatory studies showing that assimilation and coarticulation strategies are variable from speaker to speaker.

With regard to the observed reduction patterns, it has been argued that phonetic theories of coarticulation provide explanations for the contextual reduction of word-final $/ 1 /$ that are more consistent with the current data than alternative hypotheses based on phonological structural factors. This is to say that articulatory relaxation of word-final $/ 1 /$ is clearly dependent on linear phonotactic factors; however, the current results provide little evidence that the degree of reduction of $/ 1 /$ can be predicted by on the basis of syllable structure and resyllabification rules, if any at all.

Furthermore, whilst the EPG data support the generalisation that gestural conflict between contiguous articulatory targets is the main source of contextual reduction of $/ 1 /$, it appears to be the case that aerodynamic factors may also play a role in the observed reduction patterns. Nevertheless, the relative contribution of articulatory and aerodynamic factors to the reduction of $/ 1 /$ in $/ 1 \mathrm{HC} /$ contexts is not something that can be determined by EPG data alone. Establishing to what extent /1/-reduction effects (and consonantal reduction effects more generally) are by an interaction of gesturally motivated coarticulation with aerodynamically motivated coarticulation will therefore be an important line of enquiry for future research.

\section{Acknowledgments}

I am grateful to the editors of JIPA and the anonymous reviewers who commented on earlier drafts of this paper. Any remaining errors are my own.

\section{Appendix A. Carrier phrases used in the experiment}

As noted in Section 2.1.2, the carrier phrases used in the experiment were randomly varied in an attempt to minimise list-reading effects. The ten alternative phrases (in which the 3SG.PAST verb is systematically varied) were as follows:

Les dio ese

Les donó ese

Les entregó ese

Les envió ese.

Les legó ese

Les llevó ese

Les mandó ese

Les pasó ese

Les regaló ese

Les vendió ese
'S/he gave them that

'S/he donated that

'S/he handed them that

'S/he sent them that

'S/he bequeathed them that

'S/he brought them that

'S/he sent them that

'S/he passed them that

'She gave them that

'S/he sold them that

\section{Appendix B. Calculation of APC and PPC}

Measurements for the weighted contact analysis variables, APC and PPC, were calculated as follows:

Number of activated electrodes in the measurement zone

Total number of electrodes in the measurement zone 
As indicated in Figure 1, the APC-zone comprises all electrodes in rows 1-4 (i.e. a total of 30 electrodes), and the PPC-zone comprises all electrodes in rows 5-8 (i.e. a total of 32 electrodes).

\section{Appendix C. Summary of measurements}

Table A1 presents mean values for APC, PPC, TTC-Dur and /1\#C/-Dur for each of the test contexts. Corresponding standard deviation values are also included.

Table A1 Mean and SD values for APC, PPC, TTC-Dur and /1\#C/-Dur (greyed cells indicate unavailable measurements).

\begin{tabular}{|c|c|c|c|c|c|c|c|c|c|}
\hline \multirow[b]{2}{*}{ Context } & \multirow[b]{2}{*}{ Speaker } & \multicolumn{2}{|c|}{ APC } & \multicolumn{2}{|c|}{ PPC } & \multicolumn{2}{|c|}{ TTC-Dur (ms) } & \multicolumn{2}{|c|}{ /1\#C/-Dur (ms) } \\
\hline & & Mean & SD & Mean & SD & Mean & SD & Mean & SD \\
\hline \multirow[t]{4}{*}{ a. /1\#\#/ } & S1 & 0.617 & 0.104 & 0.104 & 0.064 & & & & \\
\hline & S2 & 0.564 & 0.050 & 0.185 & 0.052 & & & & \\
\hline & S3 & 0.575 & 0.073 & 0.216 & 0.085 & & & & \\
\hline & \$4 & 0.556 & 0.064 & 0.224 & 0.051 & & & & \\
\hline \multirow{5}{*}{ b. /l\#a/ } & & & & & & & & & \\
\hline & S1 & 0.413 & 0.087 & 0.221 & 0.047 & 78.5 & 12.1 & & \\
\hline & $\$ 2$ & 0.372 & 0.238 & 0.238 & 0.045 & 51.9 & 13.5 & & \\
\hline & S3 & 0.413 & 0.267 & 0.267 & 0.079 & 81.5 & 17.1 & & \\
\hline & \$4 & 0.269 & 0.209 & 0.209 & 0.037 & 60.0 & 8.4 & & \\
\hline \multirow{5}{*}{ c. $/ 1 \mathrm{\# p} /$} & & & & & & & & & \\
\hline & $\$ 1$ & 0.548 & 0.113 & 0.227 & 0.049 & 106.8 & 26.7 & 145.5 & 19.8 \\
\hline & \$2 & 0.528 & 0.243 & 0.243 & 0.054 & 97.3 & 25.1 & 139.6 & 35.6 \\
\hline & \$3 & 0.541 & 0.224 & 0.224 & 0.073 & 82.9 & 11.3 & 151.5 & 14.3 \\
\hline & $\$ 4$ & 0.267 & 0.219 & 0.219 & 0.069 & 70.8 & 16.8 & 127.7 & 24.7 \\
\hline & & & & & & & & & \\
\hline \multirow[t]{4}{*}{ d. / / \#ff/ } & $\$ 1$ & 0.485 & 0.183 & 0.183 & 0.084 & 90.0 & 17.1 & 153.5 & 12.1 \\
\hline & \$2 & 0.392 & 0.219 & 0.219 & 0.057 & 64.6 & 10.1 & 148.8 & 17.5 \\
\hline & \$3 & 0.490 & 0.171 & 0.171 & 0.066 & 81.9 & 6.6 & 174.2 & 19.9 \\
\hline & \$4 & 0.154 & 0.102 & 0.195 & 0.081 & 44.4 & 16.8 & 136.9 & 22.7 \\
\hline \multirow[t]{4}{*}{ e. $/ 1 \# \mathrm{k} /$} & S1 & 0.410 & 0.262 & 0.262 & 0.099 & 68.1 & 13.5 & 125.8 & 10.4 \\
\hline & $\$ 2$ & 0.382 & 0.250 & 0.250 & 0.053 & 65.8 & 16.9 & 137.7 & 26.1 \\
\hline & \$3 & 0.474 & 0.375 & 0.375 & 0.094 & 58.8 & 18.7 & 135.4 & 17.3 \\
\hline & S4 & 0.162 & 0.313 & 0.313 & 0.038 & 39.6 & 18.0 & 111.2 & 17.5 \\
\hline \multirow[t]{4}{*}{ f. $/ 1 \# x /$} & S1 & 0.351 & 0.171 & 0.171 & 0.068 & 58.8 & 20.9 & 145.8 & 21.8 \\
\hline & $\$ 2$ & 0.341 & 0.212 & 0.212 & 0.060 & 54.6 & 13.6 & 156.2 & 16.3 \\
\hline & S3 & 0.356 & 0.269 & 0.269 & 0.080 & 49.6 & 13.9 & 146.2 & 19.8 \\
\hline & S4 & 0.139 & 0.266 & 0.266 & 0.062 & 29.6 & 16.6 & 147.5 & 9.9 \\
\hline
\end{tabular}

\section{Appendix D. Duration of phrase-final /l/}

As stated in Footnote 3 above, TTC-Dur values could not be reliably extracted from prepausal /1/-tokens. This is because speakers showed a tendency to maintain an /1/-like contact pattern beyond the acoustic offset of the $/ 1 /$-articulation, sometimes also gradually moving the tongue to a rest position over the acoustic silence following articulation of the phrase-final $/ 1 / \mathrm{A}$ 


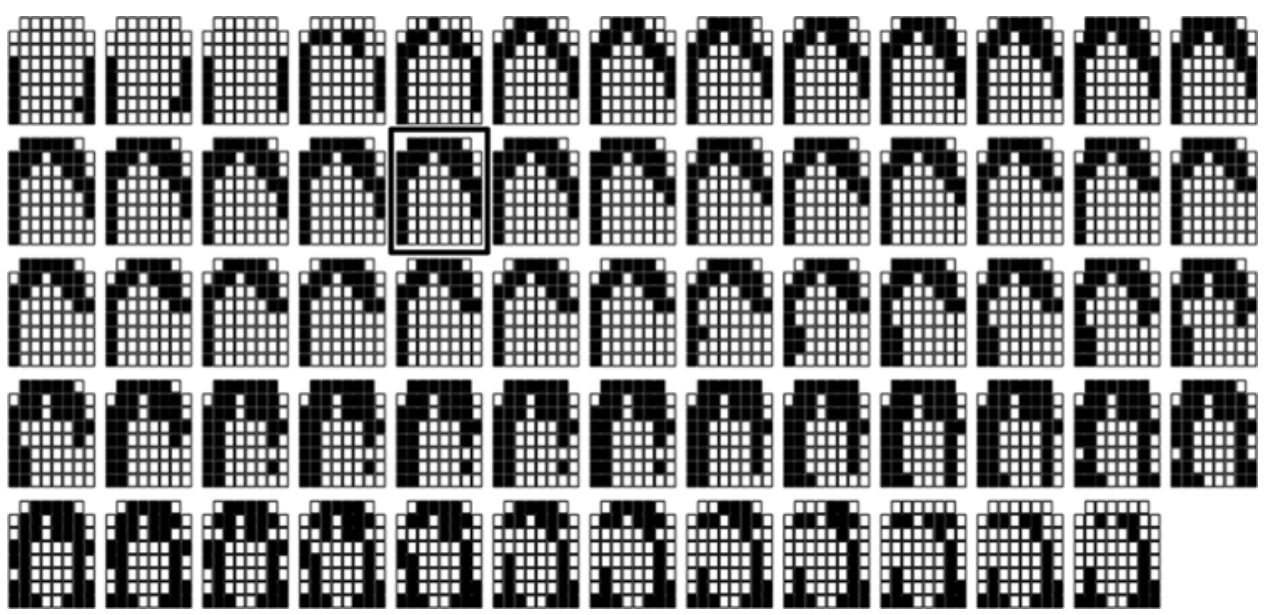

Figure A1 Palatograms extracted from a sample token of /-el\#\#/ produced by speaker S4.

sample token of this type produced by S4 is shown in Figure A1 (the palatogram coinciding with the acoustic offset of $/ 1 /$ is indicated in row 2).

An alternative measure was therefore for used to measure prepausal /1/-duration, namely the lag between the first activation of electrodes in the APC-zone and the acoustic offset of the $/ 1 /$. The latter was identified by visual inspection of the waveform and spectrogram, i.e. by determining the point of cessation of periodic voicing, the disappearance of formant structure and a corresponding drop in the intensity contour. These duration measurements therefore are based on a combination of EPG and acoustic landmarks and are not directly comparable to the TTC-Dur data presented in Section 3.2.1. Values for the alternative measurement are plotted in Figure 4 in Section 3.1.

\section{References}

Alba, Orlando. 1979. Análsis fonológico de /r/ y /1/ implosivas en un dialecto rural dominicano. Boletín de la Academia Puerrtoriqueña de la lengua española 7, 1-18.

Bates, Douglas, Martin Mächler, Ben Bolker \& Steven Walker. 2014. Ime4: Linear mixed-effects model using eigen and s4. Journal of Statistical Software.

Bermúdez-Otero, Ricardo. 2011. Cyclicity. In Marc van Oostendorp, Colin J. Ewen, Elizabeth Hume \& Keren Rice (eds.), The Blackwell companion to phonology, 2019-2048. Malden, MA: WileyBlackwell.

Bombien, Lasse, Christine Mooshammer, Philip Hoole \& Barbara Kühnert. 2010. Prosodic and segmental effects on EPG contact patterns of word-initial German clusters. Journal of Phonetics 38, 388-403.

Bybee, Joan. 2000. The phonology of the lexicon: Evidence from lexical diffusion. In Michael Barlow \& Suzanne Kemmer (eds.), Usage-based models of language, 65-85. Stanford, CA: CSLI.

Byrd, Dani. 1996. Influences on articulatory timing in consonant sequences. Journal of Phonetics 24, 209-244.

Byrd, Dani, Sungbok Lee, Daylen Riggs \& Jason Adams. 2005. Interacting effects of syllable and phrase position on consonant articulation. The Journal of the Acoustical Society of America 118, 3860-3873.

Celata, Chiara, Silvia Calamai, Irene Ricci \& Chiara Bertini. 2013. Nasal place assimilation between phonetics and phonology: An EPG study of Italian nasal-to-velar clusters. Journal of Phonetics 41, $88-100$.

Chomsky, Noam \& Morris Halle. 1968. The sound pattern of English. New York: Harper \& Row.

Colina, Sonia. 1995. A constraint-based analysis of syllabification in Spanish, Catalan and Galician. Ph.D. dissertation, University of Illinois at Urbana-Champaign. 
Colina, Sonia. 1997. Identity constraints and Spanish resyllabification. Lingua 103, 1-23.

Colina, Sonia. 2006. Optimality-theoretic advances in our understanding of Spanish syllable structure. In Fernando Martínez-Gil \& Sonia Colina (eds.), Optimality-theoretic studies in Spanish phonology, 172-204. Amsterdam: John Benjamins.

Colina, Sonia. 2009. Spanish phonology: A syllabic perspective. Washington D.C.: Georgetown University Press.

Ellis, Lucy \& William J. Hardcastle. 2002. Categorical and gradient properties of assimilation in alveolar to velar sequences: Evidence from EPG and EMA data. Journal of Phonetics 30, 373-396

Farnetani, Edda \& M. Grazia Busà. 1994. Italian clusters in continuous speech. 3rd International Conference on spoken language processing (ICSLP 94), Yokohama, 359-362.

Fernández Planas, Ana María. 2000. Estudio electropalatográfico de la coarticulación vocálica en estructuras VCV en castellano. Ph.D. dissertation, University of Barcelona.

Fougeron, Cécile \& Patricia A. Keating. 1997. Articulatory strengthening at the edges of prosodic domains. The Journal of the Acoustical Society of America 101, 3728-3740.

Freixeiro Mato, Xosé Ramón. 1998. Gramática da lingua galega I: fonética e fonología. Vigo: A nosa terra.

Gibbon, Fiona E., William J. Hardcastle \& Katerina Nicolaidis. 1993. Temporal and spatial aspects of lingual coarticulation in /k1/ sequences: A cross-linguistic investigation. Language and Speech 36, 261-277.

Gili Gaya, Samuel 1966. Elementos de fonética general. Madrid: Editorial Gredos.

Gobl, Christer \& Ailbhe Ní Chasaide. 1999. Laryngeal coarticulation (section B). In Hardcastle \& Hewlett (eds.), 122-143.

Guitart, Jorge M. 1976. Markedness and a Cuban dialect of Spanish. Washington D.C.: Georgetown University Press.

Hardcastle, William. J. 1985. Some phonetic and syntactic constraints on lingual coarticulation during /k1/ sequences. Speech Communication 4, 247-263.

Hardcastle, William J. \& William Barry. 1989. Articulatory and perceptual factors in /1/ vocalisations in English. Journal of the International Phonetic Association 15, 3-17.

Hardcastle, William J. \& Nigel Hewlett (eds.). 1999. Coarticulation: Theory, data and techniques. Cambridge: Cambridge University Press.

Hardcastle, William J., W. Jones, C. Knight, A. Trudgeon \& G. Calder. 1989. New developments in electropalatography: A state-of-the-art report. Clinical Linguistics and Phonetics 3, 1-38.

Harris, James W. 1969. Spanish phonology. Cambridge, MA: MIT Press.

Harris, James W. 1983. Syllable structure and stress in Spanish: A nonlinear analysis. Cambridge, MA: MIT Press.

Harris, James W. 1984. Autosegmental Phonology, Lexical Phonology, and Spanish nasals. In Mark Aronoff \& Richard Oehrle (eds.), Language sound structure, 67-82. Cambridge, MA: MIT Press.

Honorof, Douglas N. 1999. Articulatory gestures and Spanish nasal assimilation. Ph.D. dissertation, Yale University.

Hoole, Philip. 1999. Laryngeal coarticulation (section A). In Hardcastle \& Hewlett (eds.), 105-121.

Hualde, José Ignacio. 1991a. On Spanish syllabification. In Héctor Campos \& Fernando Martínez-Gil (eds.), Current studies in Spanish linguistics, 475-494. Washington D.C.: Georgetown University Press.

Hualde, José Ignacio. 1991b. Aspiration and resyllabification in Chinato Spanish. Probus 3, 55-76.

Hualde, José Ignacio. 2014. Los sonidos del español. Cambridge: Cambridge University Press.

Jensen, John T. 2000. Against ambisyllabicity. Phonology 17, 187-235.

Johnson, Wyn \& David Britain. 2007. L-vocalisation as a natural phenomenon: Explorations in sociophonology. Language Sciences 29, 294-315.

Josselyn, Freeman M. 1907. Études de phonétique espagnole. Maçon: Protat Frèrres.

Kaisse, Ellen. 1999. Resyllabification precedes all segmental rules: Evidence from Argentitian Spanish. In Jean-Marc Authier, Barbara. E. Bullock \& Lisa A. Reed (eds.), Formal perspectives on Romance linguistics: Selected papers from the 28th Linguistic Symposium on Romance Languages, 197-210. Amsterdam: John Benjamins. 
Keating, Patricia A., Richard Wright \& Jie Zhang. 1999. Word-level asymmetries in consonant articulation. UCLA Working Papers in Phonetics 97, 157-173.

Kochetov, Alexei \& Laura Colantoni. 2011a. Coronal place contrasts in Argentine and Cuban Spanish: An electropalatographic study. Journal of the International Phonetic Association 41(3), 313-342.

Kochetov, Alexei \& Laura Colantoni. 2011b. Spanish nasal assimilation revisited: A cross-dialect electropalatographic study. Laboratory Phonology 2, 487-523.

Kuznetsova, Alexandra, Per B. Brockhoff \& Rune H. B. Christensen. 2017. lmerTest package: Tests in linear mixed effects models. Journal of Statistical Software 82, 1-26.

Lee Kim, Sang-Im, Lisa Davidson \& Sangjin Hwang. 2013. Morphological effects on the darkness of English intervocalic /1/. Laboratory Phonology 4, 475-511.

Lipski, John M. 1989. /s/-voicing in Ecuadorean Spanish: Patterns and principles of consonantal modification. Lingua 79, 49-71.

Lipski, John M. 1990. Spanish taps and trills: Phonological structure of an isolated opposition. Folia Linguistica 3, 153-174.

Macpherson, Ian R. 1975. Spanish phonology: Descriptive and historical. Manchester: Manchester University Press.

Martínez Celdrán, Eugenio. 1991. Sobre la naturaleza fonética de los alófonos de /b, d, g/ en español y sus distintas denominaciones. Verba 18, 235-253.

Martínez Celdrán, Eugenio \& Fernández Planas, Ana María. 2007. Manual de fonética española: articulaciones y sonidos del español. L'Hospitalet de Llobregat, Barcelona: Editorial Ariel.

Mascaró, Joan. 1991. Iberian spirantization and continuant spreading. Catalan Working Papers in Linguistics 1, 167-179.

McAuliffe, Megan J., Michael P. Robb \& Bruce E. Murdoch. 2007. Acoustic and perceptual analysis of speech adaptation to an artificial palate. Clinical Linguistics and Phonetics 21, 885-894.

Navarro Tomás, Tomás. 1917. Sobre la articulación de la 1 castellana. Estudis Fonetics 1, 265-275.

Navarro Tomás, Tomás. 1957. Manual de pronunciación española. New York: Hafner Publishing Co.

Proctor, Michael. 2009. Gestural characterization of a phonological class: The liquids. Ph.D. dissertation, Yale University.

Proctor, Michael. 2011. Towards a gestural characterization of liquids: Evidence from Spanish and Russian. Laboratory Phonology 2, 451-485.

R Core Team. 2015. R: A language and environment for statistical computing. Vienna: R Foundation for Statistical Computing.

Ramsammy, Michael. 2012. The realisation of coda nasals in Spanish. Ph.D. thesis, University of Manchester.

Ramsammy, Michael. 2013. Word-final nasal velarisation in Spanish. Journal of Linguistics 49(1), 215-255.

Recasens, Daniel. 1991. On the production characteristics of apicoalveolar taps and trills. Journal of Phonetics 19, 267-280.

Recasens, Daniel. 1996. An articulatory-perceptual account of vocalization and elision of dark $/ 1 /$ in the Romance Languages. Language 39, 63-89.

Recasens, Daniel. 2004. Darkness in [1] as a scalar phonetic property: Implications for phonology and articulatory control. Clinical Linguistics and Phonetics 18, 593-603.

Recasens, Daniel \& Aina Espinosa. 2007. Phonetic typology and positional allophones for alveolar rhotics in Catalan. Phonetica 64, 1-28.

Recasens, Daniel, Jordi Fontdevila \& Maria Dolors Pallarès. 1996. Linguopalatal coarticulation and alveolar-palatal correlations for velarized and non-velarized /1/. Journal of Phonetics 24, 165-185.

Recasens, Daniel \& Maria Dolors Pallarès. 2001. Coarticulation, assimilation and blending in Catalan consonant clusters. Journal of Phonetics 29, 273-301.

Recasens, Daniel, Maria Dolors Pallarès \& Jordi Fontdevila. 1997. A model of lingual coarticulation based on articulatory constraints. The Journal of the Acoustical Society of America 102(1), 544-561.

Recasens, Daniel, Maria Dolors Pallarès \& Jordi Fontdevila. 1998. An electropalatographic and acoustic study of temporal coarticulation for Catalan dark /1/ and German clear /1/. Phonetica 55, 54-79. 
Regueira, Xosé L. 1996. Illustration of the IPA: Galician. Journal of the International Phonetic Association 26(2), 119-122.

Rubach, Jerzy. 1996. Shortening and ambisyllabicity in English. Phonology 13, 197-237.

Scobbie, James M. \& Marianne Pouplier. 2010. The role of syllable structure in external sandhi: An EPG study of vocalisation and retraction in word-final English /1/. Journal of Phonetics 38, 240-259.

Simonet, Miquel. 2010a. Rating accented speech on continua: Nativeness in speech production in highly proficient bilinguals. In Marta Ortega-Llebaria (ed.), Selected proceedings of the 4th Conference on Laboratory Approaches to Spanish Phonology, 37-46. Somerville, MA: Cascadilla Proceedings Project.

Simonet, Miquel. 2010b. Dark and clear laterals in Catalan and Spanish: Interaction of phonetic categories in early bilinguals. Journal of Phonetics 38, 663-678.

Solé, Maria-Josep. 2003. Aerodynamic characteristics of onset and coda fricatives. In M.-J. Solé, D. Recasens \& J. Romero (eds.), Proceedings of the 15th International Congress of Phonetic Sciences (ICPhS XV), Barcelona, vol. 3, 2761-2764.

Solé, Maria-Josep. 2010. Effects of syllable position on sound change: An aerodynamic study of final fricative weakening. Journal of Phonetics 38, 289-305.

Sproat, Richard \& Osamu Fujimura. 1993. Allophonic variation in English /1/ and its implications for phonetic implementation. Journal of Phonetics 21, 291-311.

Steele, Jeffrey, Laura Colantoni \& Alexei Kochetov. 2019. Gradient assimilation in French cross-word /n/+velar stop sequences. Journal of the International Phonetic Association 49(1), 87-108.

Strycharczuk, Patrycja, Marijn van 't Veer, Martine Bruil \& Kathrin Linke. 2014. Phonetic evidence on phonology-morphosyntax interactions: Sibilant voicing in Quito Spanish. Journal of Linguistics 50, 403-452.

Tollfree, Laura. 1999. South-East London English: Discrete versus continuous modelling of consonantal variation. In Paul Foulkes \& Gerard Docherty (eds.), Urban voices: Accent studies in the British Isles, 163-184. London: Arnold.

Turton, Danielle. 2014. Variation in English 1/: Synchronic reflections on the life cycle of phonological processes. Ph.D. thesis, University of Manchester.

Turton, Danielle. 2017. Categorical or gradient? An ultrasound investigation of $/ 1 /$-darkening and vocalisation in varieties of English. Laboratory Phonology 8, 1-31.

Wrench, Alan. 2003-2019. Articulate Assistant Advanced (AAA). Articulate Instruments Ltd. 